NASA/TM-2002-211702

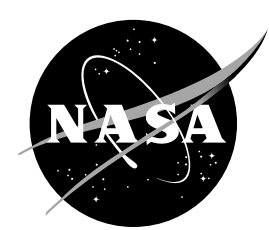

Incorporation of Mean Stress Effects Into the Micromechanical Analysis of the High Strain Rate Response of Polymer Matrix Composites

Robert K. Goldberg and Gary D. Roberts

Glenn Research Center, Cleveland, Ohio

Amos Gilat

Ohio State University, Columbus, Ohio 
Since its founding, NASA has been dedicated to the advancement of aeronautics and space science. The NASA Scientific and Technical Information (STI) Program Office plays a key part in helping NASA maintain this important role.

The NASA STI Program Office is operated by Langley Research Center, the Lead Center for NASA's scientific and technical information. The NASA STI Program Office provides access to the NASA STI Database, the largest collection of aeronautical and space science STI in the world. The Program Office is also NASA's institutional mechanism for disseminating the results of its research and development activities. These results are published by NASA in the NASA STI Report Series, which includes the following report types:

- $\quad$ TECHNICAL PUBLICATION. Reports of completed research or a major significant phase of research that present the results of NASA programs and include extensive data or theoretical analysis. Includes compilations of significant scientific and technical data and information deemed to be of continuing reference value. NASA's counterpart of peerreviewed formal professional papers but has less stringent limitations on manuscript length and extent of graphic presentations.

- TECHNICAL MEMORANDUM. Scientific and technical findings that are preliminary or of specialized interest, e.g., quick release reports, working papers, and bibliographies that contain minimal annotation. Does not contain extensive analysis.

- CONTRACTOR REPORT. Scientific and technical findings by NASA-sponsored contractors and grantees.
- CONFERENCE PUBLICATION. Collected papers from scientific and technical conferences, symposia, seminars, or other meetings sponsored or cosponsored by NASA.

- SPECIAL PUBLICATION. Scientific, technical, or historical information from NASA programs, projects, and missions, often concerned with subjects having substantial public interest.

- TECHNICAL TRANSLATION. Englishlanguage translations of foreign scientific and technical material pertinent to NASA's mission.

Specialized services that complement the STI Program Office's diverse offerings include creating custom thesauri, building customized data bases, organizing and publishing research results ... even providing videos.

For more information about the NASA STI Program Office, see the following:

- Access the NASA STI Program Home Page at http://www.sti.nasa.gov

- E-mail your question via the Internet to help@sti.nasa.gov

- Fax your question to the NASA Access Help Desk at 301-621-0134

- Telephone the NASA Access Help Desk at 301-621-0390

- Write to:

NASA Access Help Desk

NASA Center for AeroSpace Information 7121 Standard Drive

Hanover, MD 21076 
NASA/TM-2002-211702

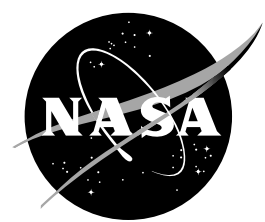

\section{Incorporation of Mean Stress Effects Into the Micromechanical Analysis of the High Strain Rate Response of Polymer Matrix Composites}

Robert K. Goldberg and Gary D. Roberts

Glenn Research Center, Cleveland, Ohio

Amos Gilat

Ohio State University, Columbus, Ohio

Prepared for the

Ninth International Conference on Composites Engineering sponsored by the International Community for Composites Engineering San Diego, California, July 1-6, 2002

National Aeronautics and

Space Administration

Glenn Research Center 
Trade names or manufacturers' names are used in this report for identification only. This usage does not constitute an official endorsement, either expressed or implied, by the National Aeronautics and Space Administration.

The Aerospace Propulsion and Power Program at NASA Glenn Research Center sponsored this work.

Available from

NASA Center for Aerospace Information 7121 Standard Drive

Hanover, MD 21076
National Technical Information Service 5285 Port Royal Road Springfield, VA 22100

Available electronically at http://gltrs.grc.nasa.gov/GLTRS 
Incorporation of Mean Stress Effects Into the Micromechanical Analysis of the High

Strain Rate Response of Polymer Matrix Composites

Robert K. Goldberg and Gary D. Roberts

National Aeronautics and Space Administration

Glenn Research Center

Cleveland, Ohio 44135

Amos Gilat

Ohio State University

Columbus, Ohio 43210

\section{Summary}

The results presented here are part of an ongoing research program, to develop strain rate dependent deformation and failure models for the analysis of polymer matrix composites subject to high strain rate impact loads. A micromechanics approach is employed in this work, in which state variable constitutive equations originally developed for metals have been modified to model the deformation of the polymer matrix, and a strength of materials based micromechanics method is used to predict the effective response of the composite. In the analysis of the inelastic deformation of the polymer matrix, the definitions of the effective stress and effective inelastic strain have been modified in order to account for the effect of hydrostatic stresses, which are significant in polymers. Two representative polymers, a toughened epoxy and a brittle epoxy, are characterized through the use of data from tensile and shear tests across a variety of strain rates. Results computed by using the developed constitutive equations correlate well with data generated via experiments. The procedure used to incorporate the constitutive equations within a micromechanics method is presented, and sample calculations of the deformation response of a composite for various fiber orientations and strain rates are discussed.

\section{Introduction}

NASA Glenn Research Center has an ongoing research program to investigate the feasibility of developing jet engine fan containment systems composed of polymer matrix composite materials. To design such a system, the ability to correctly predict the nonlinear, strain rate dependent deformation and failure of the composite under high strain rate loading conditions is required. Under these types of loading conditions, the material response can be highly strain rate dependent and nonlinear. To design a composite containment system, the ability to accurately predict the nonlinearity and strain rate dependence of the composite response is essential.

In previous work, Goldberg (ref. 1) modified the Ramaswamy-Stouffer (ref. 2) state variable constitutive equations in order to model the nonlinear, strain rate dependent deformation response of polymeric matrix materials. The constitutive equations were then implemented within a strength of materials based micromechanics model in order to 
predict the effective strain rate dependent, nonlinear deformation response of carbon fiber reinforced polymer matrix composites.

Polymers are known to have a strain rate dependent deformation response that is nonlinear above about one or two percent strain. Traditionally, viscoelasticity models have been used to capture this behavior (ref. 3). However, there has been an interest in the research community in using constitutive equations developed for metals, based on plasticity and viscoplasticity approaches, to model the nonlinear, strain rate dependent behavior of polymers and polymer matrix composites. The deformation mechanisms of polymers and metals are quite different. However, on the phenomelogical level, there are some similarities in the deformation response that could justify the use of models developed for metals to analyze polymers. For example, Ward (ref. 4) defined the "yield stress" in polymers as the stress level in a uniaxial tensile test where the stress-strain curve becomes flat and the inelastic strain rate equals the total strain rate. This definition is identical to how the "saturation stress" has been defined in state variable based constitutive models for metals (ref. 2). Furthermore, Ward (ref. 4) talks about the use of internal stresses to represent on the macroscopic level the effects of the resistance to molecular flow. Similarly, in state variable viscoplastic constitutive models for metals state variables are used (ref. 5) to represent on a macroscopic level the resistance to inelastic deformation.

There are specific examples in the literature where researchers have utilized plasticity and viscoplasticity techniques to analyze the nonlinear, strain rate dependent response of polymers and polymer matrix composites. For example, Sun and Chen (ref. 6) developed a macromechanical plasticity model based on a quadratic plastic potential function to model the nonlinear deformation of polymer matrix composites. As part of this process, the effective stress and effective plastic strain were properly defined to coincide with the plastic potential function. Weeks and Sun (ref. 7) and Thiruppukuzhi and Sun (ref. 8) expanded the methodology to incorporate rate dependence into the response. Yoon and Sun (ref. 9) modified the Bodner unified viscoplasticity model developed for metals (ref. 5) to model the nonlinear, rate dependent deformation of polymer matrix composites. Sun and Chen (ref. 10) applied plasticity theory to model the behavior of a polymer matrix, and then applied micromechanics techniques to determine the effective response of the composite. Zhang and Moore (ref. 11) adapted the Bodner model to analyze the nonlinear uniaxial tensile response of polyethylene. Bordonaro (ref. 12) and Krempl and Ho (ref. 13) adapted the viscoplasticity theory based on overstress (originally developed for metals) to analyze the nonlinear deformation of Nylon 66.

Unlike in metals, hydrostatic stresses are known to affect the yield stress and nonlinear response of polymers (ref. 4). For example, the yield stress in compression is higher than the yield stress in tension. In a simplified approach that was developed to account for these effects, the octahedral shear stress of a polymer at yield was set equal to the octahedral yield stress under pure shear loading plus a constant times the hydrostatic stress (ref. 14). In more sophisticated techniques based on the Eyring energy approach, Ward (ref. 4) proposed that the hydrostatic pressure could be added as an additional term in the equation relating the octahedral strain rate to the octahedral shear stress at yield. Ellyin, et al. (ref. 15) incorporated mean stress effects into a nonlinear viscoelastic model for polymers by adding the hydrostatic stresses to the effective stress definition. Hung and Liechti (ref. 16) incorporated mean stress effects into a macroscopic analysis of 
polymer matrix composites by incorporating an additional term including the hydrostatic stresses into Sun and Chen's (ref. 6) plasticity model. Bordonaro (ref. 12) attempted to develop a method to incorporate hydrostatic stresses into the effective stress definition to be used in constitutive models to analyze polymers based on viscoplasticity theory. Li and Pan (ref. 17), Chang and Pan (ref. 18) and Hsu, Vogler and Kyraikides (ref. 19) incorporated mean stress effects into viscoplasticity models for polymers through the application of variations of the Drucker-Prager yield criteria (ref. 20), in which mean stress effects are incorporated. By applying the new yield criteria, modified definitions of the effective stress and effective plastic strain rate were developed. While the attempts to account for the effects of hydrostatic stresses in developing yield criteria for polymers have been reasonably successful, the constitutive equations developed to model the full range of the nonlinear deformation response of polymers using plasticity and viscoplasticity techniques have not been fully successful in capturing the mean stress effects.

In previous research by the authors (ref. 1), only tensile tests of a representative polymer matrix material were available, along with tensile tests of a carbon fiber reinforced polymer matrix composite with various fiber layups. Therefore, the constitutive equations were characterized based on the matrix tensile data, and the mean stress effects were accounted for by multiplying the shear terms in the effective stress definition by a factor including the ratio of the mean stress to the second invariant of the deviatoric stress tensor $\left(\mathrm{J}_{2}\right)$ raised to a power. The value of this exponent was determined empirically by correlating the tensile response of a composite with a shear dominated fiber layup, such as $\left[ \pm 45^{\circ}\right]_{2 s}$.

The objective of the current research is to develop a more systematic, physically based method to account for the mean stress effects in the nonlinear analysis of a polymeric matrix material, where all of the material characterization is accomplished using resin data only. Furthermore, through the use of a strength of materials based micromechanics method, the nonlinear, strain rate dependent deformation of polymer matrix composites can be predicted, with the mean stress effects appropriately accounted for. In this study, first the state variable constitutive equations used to predict the strain rate dependent, nonlinear deformation of the polymer matrix are discussed, and the methods used to incorporated mean stress effects are described in detail. Next, the model is exercised by characterizing two representative polymers using tensile and shear data over a variety of strain rates. The deformation response of the polymers is then computed to demonstrate the ability of the model to accurately compute the polymer behavior. The implementation of the constitutive equations within a strength of materials based micromechanics method is then presented, and the nonlinear, strain rate dependent deformation response of a representative polymer matrix composite is predicted.

\section{Polymer Constitutive Equations}

\section{Overview}

For this study, the Bodner state variable constitutive equations (ref. 5), which were originally developed to analyze the viscoplastic deformation of metals above one-half of the melting temperature, were modified to analyze the strain rate dependent, nonlinear deformation of the polymeric matrix material. In state variable constitutive equations, a 
single unified strain variable is defined to represent all inelastic strains (ref. 2).

Furthermore, in the state variable approach there is no defined yield stress. Inelastic strains are assumed to be present at all values of stress, only at a very small level in the "elastic" range of deformation. State variables, which evolve with stress and inelastic strain, are defined to represent the average effects of the deformation mechanisms.

In previous research on this project (ref. 1), the Ramaswamy-Stouffer model (ref. 2) was used as the basis for the polymer constitutive equations. In the Ramaswamy-Stouffer equations as used in reference 1 , the components of the inelastic strain rate were a function of the overstress, the difference between the deviatoric stress components and the components of the tensorial internal stress state variable. A material constant in the equations represented any initial isotropic hardness of the material. In the Bodner equations (as used and modified for this study) on the other hand, the components of the inelastic strain rate are a function of the deviatoric stresses only, not the overstress, and the resistance to inelastic deformation is represented through a single, isotropic, state variable. This formulation allows for a more systematic modification of the effective stress definitions in order to account for the mean stress effects. Furthermore, as discussed in Qian and Liu (ref. 21) for example, one can argue that in the initial stages of polymer deformation an isotropic resistance to molecular flow (simulating a nonlinear viscosity) more accurately represents the actual polymer behavior.

Several limitations and assumptions have been specified in the development of the constitutive equations. Currently temperature effects are neglected. While the deformation response of polymers varies significantly with temperature, only room temperature data have been obtained at this time, so the effects of temperature are not considered. However, since temperature effects can be significant, particularly when considering thermal stresses in polymer matrix composites, this capability will be added in the future. Moisture effects, while possibly significant in polymer matrix composites, are also not included at the current time but may be added in the future. The nonlinear strain recovery observed in polymers on unloading is not simulated, and phenomena such as creep, relaxation and high cycle fatigue are not currently accounted for in the equations. However, since mean stress effects are important even in metals for the analysis of high cycle fatigue (ref. 22), in the future if fatigue analysis capabilities are added to the constitutive equations for polymers the mean stress effects will likely be even more significant. Small strain theory is assumed to apply in the current analysis.

\section{Flow and Evolution Equations}

In the modified Bodner model, the components of the inelastic strain rate $\dot{\varepsilon}_{i j}^{I}$ are defined as a function of the deviatoric stress components $\mathrm{s}_{\mathrm{ij}}$, the second invariant of the deviatoric stress tensor $J_{2}$ and an isotropic state variable $Z$ which represents the resistance to molecular flow (internal stress) in the form

$$
\dot{\varepsilon}_{i j}^{I}=D_{o} \exp \left[-\frac{1}{2}\left(\frac{Z}{\sigma_{e}}\right)^{2 n}\right]\left(\frac{s_{i j}}{\sqrt{J_{2}}}\right)
$$

where $D_{o}$ and $n$ are material constants. $D_{o}$ represents the maximum inelastic strain rate, and $\mathrm{n}$ controls the rate dependence of the material. The elastic components of strain are 
added to the inelastic strain to obtain the total strain. The term $\sigma_{\mathrm{e}}$ represents the effective stress state in the material, and was modified from the original formulation (ref. 5) in order to account for the effects of hydrostatic stresses in a polymeric material. Based on the formulation used by Chang and Pan (ref. 18) and Hsu, et al. (ref. 19), the effective stress is defined as follows in this work in order to account for the effects of hydrostatic stresses

$$
\sigma_{e}=\sqrt{3 J_{2}}+\alpha \sigma_{k k}
$$

where $\alpha$ is a state variable controlling the level of the mean stress effects and $\sigma_{\mathrm{kk}}$ is the summation of the normal stress components (equal to three times the mean stress). This formulation of the effective stress is based on the Drucker-Prager (ref. 20) yield criteria. Under pure shear loading, the mean stress is equal to zero and the equation reduces to the original formulation (ref. 5), in which the effective stress was set equal to $\sqrt{3 J_{2}}$ for all loading conditions.

The rate of evolution of the internal stress state variable $\mathrm{Z}$ and the mean stress effect state variable $\alpha$ are defined by the equations

$$
\begin{aligned}
& \dot{Z}=q\left(Z_{1}-Z\right) \dot{e}_{e}^{I} \\
& \dot{\alpha}=q\left(\alpha_{1}-\alpha\right) \dot{e}_{e}^{I}
\end{aligned}
$$

where $\mathrm{q}$ is a material constant representing the "hardening" rate, and $Z_{1}$ and $\alpha_{1}$ are material constants representing the maximum values of $Z$ and $\alpha$, respectively. The initial values of $Z$ and $\alpha$ are defined by the material constants $Z_{\mathrm{o}}$ and $\alpha_{\mathrm{o}}$. The term $\dot{e}_{e}^{I}$ in Equations 3 and 4 represents the effective deviatoric inelastic strain rate, defined as follows

$$
\begin{aligned}
\dot{e}_{e}^{I} & =\sqrt{\frac{2}{3} \dot{e}_{i j}^{I} \dot{e}_{i j}^{I}} \\
\dot{e}_{i j}^{I} & =\dot{\varepsilon}_{i j}^{I}-\dot{\varepsilon}_{m}^{I}
\end{aligned}
$$

where $\dot{\varepsilon}_{i j}^{I}$ are the components of the inelastic strain rate tensor and $\dot{\varepsilon}_{m}^{I}$ is the mean inelastic strain rate. In the original Bodner model (ref. 5), the total inelastic strain and strain rate are used in the evolution law and are assumed to be equal to their deviatoric values. As discussed by Li and Pan (ref. 17), since mean stresses contribute to the inelastic strains in polymers, indicating volumetric effects are present, the mean inelastic strain rate cannot be assumed to be zero, as in the case in the inelastic analysis of metals. An important point to note is that in the original Bodner model (ref. 5), the inelastic work rate was used instead of the effective inelastic strain rate in the evolution equation for the internal stress state variable. However, for this work the inelastic strain rate was deemed easier to work with from both computational and characterization points of view, particularly in the incorporation of mean stress effects. Furthermore, the inelastic strain 
rate has been used in other state variable constitutive models (ref. 2), and as will be shown later, the equations as given produced good results. Since hydrostatic stress effects were not considered in the original Bodner model (ref. 5), the evolution equation for $\alpha$ is new to this work. The state variable $\alpha$ is assumed to evolve in the same manner as the state variable $Z$. As will be pointed out later, by using this assumption the value of q used in Equation 3 will be the same as the value of q used in Equation 4.

\section{Determination of Material Constants}

The material constants that need to be determined include $D_{0}, n, Z_{0}, Z_{1}, \alpha_{0}, \alpha_{1}$, and q. The procedure to be used is summarized here. More details on the general approach can be found in Stouffer and Dame (ref. 2) and Bodner (ref. 5). The values of $\mathrm{D}_{0}, \mathrm{n}$, and $\mathrm{Z}_{1}$ are characterized as follows using Equation 1. The value of $D_{0}$ is currently assumed to be equal to a value of $10^{4}$ times the maximum applied strain rate, which correlates with the maximum inelastic strain rate. Equation 1 is simplified to the case of pure shear loading, leading to the following expression

$$
\dot{\gamma}^{I}=2 D_{0} \exp \left[-\frac{1}{2}\left(\frac{Z}{\sqrt{3}|\tau|}\right)^{2 n}\right] \frac{\tau}{|\tau|}
$$

where $\dot{\gamma}^{I}$ is the engineering shear strain rate, $\tau$ is the shear stress, and the remainder of the terms are as defined earlier. The case of pure shear loading is used to characterize the equations for two reasons. First, mean stress effects are not present in the case of pure shear loading, so those material constants do not enter into the picture, simplifying the initial characterization. Second, since polymers tend to be more ductile in shear than in uniaxial tension, the pure shear stress-strain curves obtained experimentally are more likely to display a defined "saturation" stress, which as shown below is crucial for determining the material constants. If only uniaxial tensile and compressive curves are available, procedures will be given later for determining the equivalent shear stresses at saturation.

Next, Equation 6 is rearranged as follows

$$
-2 \ln \left(\frac{\dot{\gamma}^{I}}{2 D_{0}}\right)=\left(\frac{Z}{\sqrt{3}|\tau|}\right)^{2 n}
$$

and the natural logarithm of both sides of the resulting expression is taken. The values of the inelastic shear strain rate, shear stress, and state variable Z at "saturation" or "yield" are substituted into the resulting expression, resulting in the following equation

$$
\ln \left[-2 \ln \left(\frac{\dot{\gamma}_{o}}{2 D_{0}}\right)\right]=2 n \ln \left(Z_{1}\right)-2 n \ln \left(\sqrt{3} \tau_{s}\right)
$$


where $\tau_{\mathrm{s}}$ equals the saturation shear stress, $\dot{\gamma}_{o}$ is the constant applied total engineering shear strain rate in a constant strain rate shear test, and the remaining terms are as defined earlier.

The required constants are determined from a set of shear stress-strain curves obtained from constant strain rate tests. Each curve in this set is obtained at a different constant strain rate. Data pairs of the total strain rate and saturation shear stress values from each curve are taken. For each strain rate, the data values are substituted into Equation 8, and represent a point on a master curve. The number of points in the master curve equal the number of strain rates at which tensile tests were conducted. A least squares regression analysis is then performed on the master curve. As suggested by Equation 8, the slope of the best-fit line is equal to $-2 n$. The intercept of the best-fit line is equal to $2 n\left(\ln \left(Z_{1}\right)\right)$.

To determine the value of $Z_{0}$, first Equation 7 is rearranged as follows

$$
Z=\left(-2 \ln \left(\frac{\dot{\gamma}^{I}}{2 D_{o}}\right)^{\frac{1}{2 n}} \sqrt{3} \tau\right.
$$

where all of terms are as defined earlier. To find the value of $Z_{0}$ from Equation 9, the value of the shear stress where the stress-strain curve becomes nonlinear for a particular constant strain rate shear test is used for the value of $\tau$. The point where the stress-strain curve becomes nonlinear is defined as the approximate point where the curve appreciably deviates from a linear extrapolation of the initial data. The value of $\dot{\gamma}^{I}$ is set equal to the approximate inelastic shear strain rate when the stress-strain curve becomes nonlinear. The shear strain rate used in the test divided by 100 was found by trial and error to approximate this value reasonably well. Using this data, Equation 9 is solved for Z, which is assumed to be equal to the value of $Z_{0}$. Using the data from the lowest strain rate test available has been found to give adequate values of $Z_{0}$. However, the calculations can be made using data from all the available strain rates, and an average taken if required to obtain the value of the constant.

To determine the value for q for Equations 3 and 4, first Equation 3 is integrated for the case of pure shear loading, resulting in the following relation

$$
Z=Z_{1}-\left(Z_{1}-Z_{o}\right) \exp \left(\frac{-q}{\sqrt{3}} \gamma^{I}\right)
$$

where $\gamma^{\mathrm{I}}$ is the inelastic shear strain. At saturation, the value of the internal stress $Z$ is assumed to approach $Z_{1}$, resulting in the exponential term approaching zero. Assuming that saturation occurs when the following condition is satisfied

$$
\exp \left(\frac{-q}{\sqrt{3}} \gamma_{s}^{I}\right)=0.01
$$

the equation is solved for $\mathrm{q}$, where $\gamma_{\mathrm{s}}{ }_{\mathrm{s}}$ is the inelastic shear strain at saturation. If the inelastic shear strain at saturation is found to vary with strain rate, the parameter $q$ is 
computed at each strain rate and regression techniques are utilized to determine an expression for the variation of q. If Equation 4 is integrated, an expression similar to Equation 10 is obtained. At saturation, the value of $\alpha$ is assumed to approach $\alpha_{1}$, so an equation identical to Equation 11 is obtained, which would lead to the same value for q. Therefore, identical values of $\mathrm{q}$ are used in Equation 3 and Equation 4.

To obtain the values of $\alpha_{1}$ and $\alpha_{0}$, Equation 2 is used in combination with stress-strain data from constant strain rate uniaxial tensile tests and constant strain rate shear tests. The primary assumption used at this point (and assumed implicitly in Equation 2) is that the effective stress at saturation under uniaxial tensile loading at a particular strain rate is equal to the effective stress at saturation under pure shear loading at the same equivalent strain rate. Likewise, the effective stress at the point the stress-strain curve becomes nonlinear under tensile loading is equal to the effective stress at the point the stress-strain curve becomes nonlinear under shear loading. Therefore, assuming the value of $\alpha$ at saturation is equal to $\alpha_{1}$, and the value of $\alpha$ at the point the stress-strain curve becomes nonlinear is equal to $\alpha_{0}$, the following equations are obtained for the case of having data from uniaxial tension tests and pure shear tests

$$
\begin{gathered}
\sigma_{s}\left(1+\alpha_{1}\right)=\sqrt{3} \tau_{s} \\
\sigma_{n l}\left(1+\alpha_{o}\right)=\sqrt{3} \tau_{n l}
\end{gathered}
$$

where $\sigma_{\mathrm{s}}$ and $\tau_{\mathrm{s}}$ are the tensile and shear stresses at saturation, respectively, and $\sigma_{\mathrm{nl}}$ and $\tau_{\mathrm{nl}}$ are the tensile and shear stresses at the point where the respective stress-strain curves become nonlinear. The required constants can then be determined from these equations. The values of the material constants are assumed to be rate independent, so the results from only one strain rate need to be used to find the needed parameters. In practical application of the methodology, the uniaxial tension and pure shear tests used do not have to be at the exact same effective strain rate. As long as the effective strain rates from the two tests are approximately equal, the values obtained have been found to be valid.

Similar procedures can be used to determine the values of $\alpha_{1}$ and $\alpha_{0}$ based on the results of uniaxial tension and uniaxial compression tests, as well as uniaxial compression and pure shear tests. If pure shear tests are not available, but the results of constant strain rate uniaxial tension and constant strain rate uniaxial compression tests at several strain rates are available, as just mentioned Equation 2 can be used to obtain the values of $\alpha_{1}$ and $\alpha_{\mathrm{o}}$ in a manner similar to that described above. A procedure similar to that described in Equations 6-11 could then be used with either the tensile or compressive data to obtain the remainder of the material constants.

Numerical Integration of Constitutive Equations

To integrate the flow and evolution equations in a computer algorithm, a standard fourth order Runge-Kutta integration routine was used (ref. 23). For this class of equations, implicit integration routines have often been used because of their inherent numerical stability (ref. 2). However, to be able to use the equations in impact studies, the equations will need to be implemented into a transient dynamic finite element code, which uses explicit integration schemes. Therefore, an explicit integration scheme was 
used here in order to facilitate the eventual finite element implementation. The RungeKutta method was employed for this study due to its simplicity and ease of implementation. Strain controlled loading was assumed in the algorithm in order to facilitate the eventual implementation of these equations into an explicit finite element code. In addition, the tensile and shear tests conducted in this study were carried out at constant strain rate. Therefore, using a strain controlled loading algorithm simplified the analytical simulation of the experiments.

To determine the values of the total strain, inelastic strain, internal stress and mean stress effect state variable at time $\mathrm{t}+\Delta \mathrm{t}$, the following algorithm is used for each step of the Runge-Kutta integration. The strains or strain estimates are passed into the routine. The stresses are then computed using the elastic constants and the current value of the inelastic strains. The effective stress is then determined using Equation 2, and the components of the inelastic strain rate tensor are calculated using Equation 1. From this information, the effective deviatoric inelastic strain rate is determined using Equation 5, and the state variable rates are computed using Equations 3 and 4. The elastic constants and the inelastic strain rates are then used to determine the total strain rates. The RungeKutta algorithm is then used to calculate the revised total and inelastic strains and the new values of the state variables.

\section{Simulation of Strain Rate Dependent Polymer Shear and Tensile Deformation}

To demonstrate the ability of the developed constitutive equations to correctly analyze the mean stress dependent deformation response of polymers, two representative materials were analyzed. The first material, PR520, is a toughened epoxy. The second material, E-862, is a standard brittle epoxy. By examining these materials, the ability of the constitutive model to correctly analyze a variety of polymers could be examined. Details of the experimental procedure and experimental results will be given in a future report. However, a summary is given here for completeness. Longitudinal tensile tests and pure shear tests were conducted at room temperature on the materials at strain rates of about $5 \times 10^{-5} / \mathrm{sec}, 1 / \mathrm{sec}$ and $400 / \mathrm{sec}$. The low and moderate strain rate tests were conducted using an Instron hydraulic testing machine. The high strain rate tests were conducted using a split Hopkinson bar. Engineering stress and engineering strain were measured until failure.

Shear stress-shear strain curves for PR520 obtained under pure shear loading are shown in Figure 1 for each of the strain rates examined, while tensile stress-strain curves are shown in Figure 2. The material has a strain rate dependent, nonlinear deformation response under both types of loading. For the shear tests at high strain rates, the sharp increase in stress at the beginning of the loading with negligible increase in strain is most likely the result of a lack of stress equilibrium at the start of loading. The oscillations seen in the tensile response at high strain rates are most likely due to the specimen geometry leading to the stress waves being visible in the response. The failure stresses under tensile loading appear not to vary with strain rate. The causes of this are still under investigation. Physical reasons for the constant failure stresses may be related to a ductile-brittle transition taking place as the strain rate is increased. However, particularly for the high strain rate tests, the failure stresses may be artificially low due to the presence of strain gages on the specimen. Shear stress-shear strain curves for E-862 for 
all three strain rates are shown in Figure 3, and tensile stress-strain curves are shown in Figure 4. The shear stress-strain curves display significant nonlinearity and strain rate dependence. The tensile specimens at the moderate and high strain rate show a very low failure stress, much lower than that seen for the low strain rate specimen. The specific reasons for this are still being studied, but preliminary investigations not discussed here indicate that the premature failure may be due to the presence of the strain gages and how they are glued onto the specimen. The other features of the deformation response of E-862 are similar to those observed for PR520. Again, a detailed discussion of the experimental results will be given in a future report. The material constants for both polymers were determined using the procedures described earlier in this report and are listed in Table 1.

The shear stress-shear strain curves computed for all three strain rates, along with the experimental results for comparison, are shown in Figure 5 for PR520 and Figure 6 for E-862. Overall, the computed results correlate well with the experimental values for all strain rates for both materials. Specifically, the nonlinearity and rate dependence of the experimental results are captured qualitatively, and the quantitative match between the experimental and computed results is reasonably good. The high strain rate results are somewhat underpredicted for both materials (particularly for E-862), particularly at the lower strains, but this is due to the fact that in the experiments the initial stresses increased significantly with a negligible increase in strain, and thus the initial modulus of the material was computed using data obtained after the strain became non-negligible. Further tests are being conducted in order to obtain refined stress strain curves that do not have this problem. The overall computed shape of the curves, and the final computed saturation stresses, compare well with the experimental results, however.

The tensile stress-strain curves computed for all three strain rates, again with the experimental results for comparison, are shown in Figure 7 for PR520 and Figure 8 for E-862. Once again, the computed results correlate well with the experimental values for all three strain rates. The nonlinearity and rate dependence of the experimental results is captured, and the quantitative comparison between the experimental and computed results is again good. In the case of the high strain rate results, the oscillated results are bisected well by the computed values. For the tensile results, the important point to note is that the material constants were primarily computed using the shear data, and the comparison of the tensile data to the computed results is still quite good.

To further explore the significance of properly accounting for the mean stress effects in the analysis, the tensile stress-strain curve for PR520 at the low strain rate of $5 \times 10^{-5} / \mathrm{sec}$ is once again considered. In Figure 9, the experimental stress-strain curve, along with the original computed curve, is presented. Two additional computed results are given in the figure. First, a tensile curve computed without the mean stress effect included $\left(\alpha_{0}=\alpha_{1}=0\right)$ is given. Second, a set of results computed with a constant $\alpha$ (set equal to $\alpha_{1}$ ) is presented. The tensile curve computed without accounting for mean stress effects significantly overpredicts the stresses as compared to the experimental results, indicating that mean stress effects are significant for polymers, and accounting for them in an analysis is crucial. Furthermore, in the results computed assuming a constant $\alpha$ the stresses are overpredicted compared to the experimental values for a significant portion of the nonlinear region of the tensile curve. In most of the attempts by other researchers to account for the effects of hydrostatic stresses described in the first section of this 
report, the mean stress effects were assumed to be constant (reflected in a static material property) throughout the course of the deformation. These results indicate that the effect of the mean stresses does vary throughout the polymer deformation, and must be accounted for in the analysis.

\section{Composite Micromechanical Analysis}

Micromechanical techniques are used to predict the effective properties and deformation response of the individual plies in a composite laminate. The effective properties and deformation response are computed based on the properties of the individual constituents. Lamination theory can then be used to compute the effective deformation response of the entire composite. The constitutive equations described above have been implemented within a micromechanics method in order to enable the prediction of the nonlinear, strain rate dependent deformation response of polymer matrix composites with the effects of hydrostatic stresses incorporated into the analysis. The micromechanics method has been described extensively in Goldberg (ref. 24). A summary of the methodology will be given here.

For this work the unit cell, the smallest material unit for which the response can be considered to be representative of the entire composite ply, is defined to consist of a single fiber and its surrounding matrix. Due to symmetry, only one-quarter of the unit cell was analyzed. The composites are assumed to have a periodic, square fiber packing and a perfect interfacial bond is specified. The fibers are assumed to be transversely isotropic and linear elastic with a circular cross-section. The matrix is assumed to be isotropic, with a rate dependent, nonlinear deformation response computed using the equations described in the previous section of this report. A key assumption of this approach is that the in-situ matrix properties are equivalent to the bulk properties of the polymer. However, the advantage of using this type of methodology is that it is simpler to conduct experiments on the pure resin and to determine the material constants from the pure resin data as opposed to trying to back out the resin properties from composite test data. Furthermore, a key goal of this research is to provide a methodology that facilitates reducing the amount of testing of the composite that is required to obtain strain rate dependent material properties that can be input into a finite element code. Conducting strain rate dependent tensile tests on the pure resin and using that data to predict the composite deformation response is also much simpler than conducting tests on the composite. However, if in comparing test data obtained from composite specimens to analytical predictions it appears that the bulk matrix properties do not accurately reflect the in-situ state of the matrix, the polymer properties can always be appropriately adjusted.

The unit cell is divided up into an arbitrary number of rectangular, horizontal slices of equal thickness, as is shown in Figure 10. Similar approaches have been used by researchers such as Whitney (ref. 25), Greszczuk (ref. 26) and Mital, et al. (ref. 27). Each slice is assumed to be in a state of plane stress. This assumption is made based on the fact that laminate theory will be applied to each ply of the composite laminate, which implies that the unit cell and every slice within the unit cell is in a state of plane stress. The top and bottom slices in the unit cell are composed of pure matrix. The remaining slices are composed of two subslices; one composed of fiber material and the other 
composed of matrix material. For the slices containing both fiber and matrix, the out-ofplane stresses can be nonzero in individual subslices, but the volume average of the outof-plane stresses must be equal to zero. By using this approach, the behavior of each slice is decoupled, and the response of each slice can be determined independently, which significantly reduces the level of complexity in the analysis. Laminate theory is then used to obtain the effective response of the unit cell. In the future, the ability to incorporate transverse shear stresses and transverse pressures will be added to the model as these loading conditions might be significant in an impact analysis. In this case, the out-of-plane stresses would be constant throughout the unit cell.

The thickness, fiber volume ratio and thickness ratio (the ratio of the slice thickness to the total unit cell thickness) for each slice can be determined using the composite fiber volume ratio and geometric principles. The unit cell is assumed to measure one unit in length by one unit in height. The first step is to compute the area of the cross-section of the fiber within each slice. The overall diameter of the fiber $\left(d_{f}\right)$ is related to the fiber volume fraction of the overall composite $\left(\mathrm{V}_{\mathrm{f}}\right)$ through the following relationship

$$
d_{f}=\sqrt{\frac{4 V_{f}}{\pi}}
$$

and this term can be used along with the standard geometric definition of the radius of a circle to compute the horizontal coordinate of any point on the outer surface of the fiber in terms of the fiber volume fraction and the vertical coordinate. The area of the portion of the fiber contained within each slice $\left(\mathrm{A}_{\mathrm{f}}^{\mathrm{i}}\right)$ can computed by integrating the resulting expression between the vertical (z) coordinates of the top and bottom of slice " $i$ "

$$
A_{f}^{i}=\int_{z_{i-1}}^{z_{i}} \sqrt{\frac{V_{f}}{\pi}-z^{2}} d z
$$

which is also the equivalent area of the rectangular fiber slice in the analysis cell.

The fiber volume fraction of each slice composed of fiber and matrix is equal to the fiber area in each slice divided by the total slice area. The thickness ratio for each slice composed of both fiber and matrix is equal to the slice thickness divided by the assumed total height of the analysis cell. The fiber volume fraction of the top slice consisting of matrix only is equal to zero, and the thickness ratio of the top slice is equal to one minus the sum of the thickness ratio of the remaining slices.

The effective properties, effective inelastic strains and effective thermal strains of each slice are computed independently. The responses of each slice are combined using laminate theory to obtain the effective response of the corresponding lamina. Micromechanics equations are developed for those slices composed of both fiber and matrix material. The stresses in the slices composed of pure matrix can be computed using the matrix elastic properties and inelastic constitutive equations. The standard transversely isotropic compliance matrix (or isotropic in the case of the matrix) is used to relate the local strains to the local stresses in the fiber and matrix. Each slice is assumed to be in a state of plane stress on the global level, but out-of-plane normal stresses can exist in each subslice. 
Along the fiber direction (direction 11), the strains are assumed to be uniform in each subslice, and the stresses are combined using volume averaging. The in-plane transverse normal stresses (22 direction) and the in-plane shear stresses (12 direction) are assumed to be uniform in each subslice, and the strains are combined using volume averaging. The out-of-plane strains (33 direction) are assumed to be uniform in each subslice. The volume average of the out-of-plane stresses in each subslice is assumed to be equal to zero, enforcing a plane stress condition on the global level for the slice.

The orthotropic compliance matrix is used to relate the strains $\left(\varepsilon_{\mathrm{ij}}\right)$ to the stresses $\left(\sigma_{\mathrm{ij}}\right)$ in each constituent, using the following relations

$$
\begin{gathered}
\left\{\begin{array}{l}
\varepsilon_{11} \\
\varepsilon_{22} \\
\varepsilon_{33}
\end{array}\right\}=\left[\begin{array}{lll}
S_{11} & S_{12} & S_{13} \\
S_{12} & S_{22} & S_{23} \\
S_{13} & S_{23} & S_{33}
\end{array}\right]\left\{\begin{array}{l}
\sigma_{11} \\
\sigma_{22} \\
\sigma_{33}
\end{array}\right\}+\left\{\begin{array}{l}
\varepsilon_{11}^{I} \\
\varepsilon_{22}^{I} \\
\varepsilon_{33}^{I}
\end{array}\right\}+\left\{\begin{array}{l}
\alpha_{11} \\
\alpha_{22} \\
\alpha_{33}
\end{array}\right\} \Delta T \\
\gamma_{12}=S_{66} \sigma_{12}+2 \varepsilon_{12}^{I}
\end{gathered}
$$

where $\alpha_{11}, \alpha_{22}$, and $\alpha_{33}$ are the coefficients of thermal expansion, $\Delta \mathrm{T}$ is the change in temperature and $\varepsilon_{\mathrm{ij}}{ }^{\mathrm{I}}$ are the inelastic strains. Note that in these equations $\mathrm{S}_{\mathrm{ij}}$ represents the components of the compliance matrix, not the components of the deviatoric stress tensor $\mathrm{s}_{\mathrm{ij}}$ as in the description of the polymer constitutive equations and that the coefficients of thermal expansion $\alpha_{i j}$ have no relation to the material constants $\alpha_{1}$ and $\alpha_{\mathrm{o}}$ in the polymer model. Also note that engineering shear strains $\left(\gamma_{\mathrm{ij}}\right)$ are used in the analysis.

The addition of the inelastic strain components to the standard orthotropic elastic constitutive law facilitates the incorporation of inelasticity into the constitutive relations. For the fiber, which is assumed to be linear elastic, these components are neglected. For the fiber, which is transversely isotropic, $S_{13}$ is set equal to $S_{12}$ and $S_{33}$ is set equal to $S_{22}$. For the matrix material, which is assumed to be isotropic, $S_{23}$ and $S_{13}$ are set equal to $S_{12}$, and $S_{22}$ and $S_{33}$ are set equal to $S_{11}$. Furthermore, $\alpha_{33}$ is set equal to $\alpha_{22}$ for the fiber and $\alpha_{33}$ and $\alpha_{22}$ are set equal to $\alpha_{11}$ for the matrix.

By combining the uniform stress and uniform strain assumptions with the constituent stress-strain relations, a system of four simultaneous equations results that can be solved for the unknown stresses in the subslices. The total strains and subslice inelastic strains are considered to be the known values in solving this problem. By substituting the subslice stresses back into the equations defining the uniform stress assumptions, the effective elastic constants, effective inelastic strains and effective thermal strains of the slice can be computed. By applying classical laminate theory at this point, the effective stiffness matrix, effective inelastic strains and effective thermal strains for the unit cell are computed. Laminate theory is applied once again to obtain the effective properties and force resultants due to inelastic and thermal strains for the multilayered composite laminate. Further information on all of these procedures can be found in Goldberg (ref. 24). 


\section{Simulation of Strain Rate Dependent Composite Deformation}

To verify the ability of the micromechanics equations combined with the revised polymer constitutive equations to accurately model the deformation response of polymer matrix composites, a series of analyses have been carried out on a representative composite. Experimental tests have not yet been conducted on composites made using either of the polymers (PR520 and E-862) described in the previous section. Therefore, data from literature was used to verify the implementation of the revised polymer constitutive equations into the micromechanics framework. A PEEK thermoplastic matrix was characterized using the procedures described earlier based on data in Hsu, et al. (ref. 19) and the material constants are listed in Table 1. Experimental (ref. 19) and computed compressive stress-strain curves are shown for the PEEK matrix in Figure 11. The computed stress-strain curves capture the rate dependence and nonlinearity of the experimental results, and the quantitative comparison between the experimental and computed results is quite good. These results further demonstrate the ability of the polymer constitutive equations to analyze the deformation response of a wide variety of polymers (epoxies, toughened epoxies and thermoplastics). The composite material examined consists of AS4 carbon fibers embedded in a PEEK matrix. Tensile curves were obtained by Weeks and Sun (ref. 7) for composites with a variety of laminate orientations at strain rates of $1 \times 10^{-5} / \mathrm{sec}$ and $0.1 / \mathrm{sec}$. The fiber volume ratio of the AS4/PEEK composite is 0.62 . The elastic properties of the AS4 fibers (ref. 28) include a longitudinal tensile modulus of $214 \mathrm{GPa}$, a transverse tensile modulus of $14 \mathrm{GPa}$, a longitudinal Poisson's ratio of 0.20, a transverse Poisson's ratio of 0.25, and an in-plane shear modulus of $28 \mathrm{GPa}$. As mentioned earlier, while thermal and moisture effects may affect the deformation response in polymer matrix composites, since temperature and moisture dependent data was not available for the matrix materials under consideration, and since these effects were not accounted for within the polymer constitutive equations at the current time, thermal and moisture effects were neglected for these analyses. The effects of temperature and moisture are merely noted as a possible source of error in the current computations.

Experimental and computed longitudinal tensile stress-strain curves for AS4/PEEK at room temperature at strain rates of $0.00001 / \mathrm{sec}$ and $0.1 / \mathrm{sec}$ are shown in Figures 12 and 13. Only relatively low strain rates were examined due to the lack of available high strain rate data for this material and its matrix constituent. Also, note that the tensile curves are not necessarily taken until failure. Furthermore, the current analytical model does not make failure predictions. In Figure 12 results for laminates with a $\left[30^{\circ}\right]$ fiber orientation are shown and in Figure 13 results for laminates with a $\left[45^{\circ}\right]$ fiber orientation are shown. With these fiber orientations, the matrix in the composite is subjected to a multiaxial stress state, with tensile, compressive, and shear stresses, and as a result the ability of the micromechanics method in combination with the polymer constitutive equations to accurately capture the mean stress effects in the polymer deformation (and by extension the composite deformation) could be examined. As can be seen in both figures, the nonlinearity and strain rate dependence of the composite deformation as well as the shape of the curves are captured by the analysis. Quantitatively, the match between the experimental and computed results is also reasonably good. The stresses for 
the $\left[45^{\circ}\right]$ laminate at the lower strain rate are somewhat overpredicted for reasons that are not clear at this time, but otherwise the computed stresses closely match the experimental stresses. Since for the laminate orientations examined both tensile and shear stresses are present in the composite, the analytical results indicate that the mean stress effects are also being captured correctly.

\section{Conclusions}

An analytical model has been developed to analyze the strain rate dependent, nonlinear deformation of polymers and polymer matrix composites in which the effects of hydrostatic stresses on the nonlinear deformation are systematically accounted for. State variable constitutive equations based on the Bodner viscoplasticity model have been modified to analyze the deformation of polymer matrix materials. The effects of hydrostatic stresses on the inelastic deformation have been accounted for by modifying the effective stress and effective plastic strain definitions through the use of a variation of the Drucker-Prager yield criterion. The tensile and shear deformation of two representative polymers have been accurately simulated using the constitutive model.

The constitutive equations have been implemented within a mechanics of materials based micromechanics method that employs fiber substructuring to enable the prediction of the strain rate dependent, nonlinear deformation of polymer matrix composites. The longitudinal tensile deformation of a representative polymer matrix composite was accurately predicted for two laminate orientations and two strain rates, indicating that the analysis is correctly capturing the important features of the deformation response.

The analytical methods described in this study can be used in explicit finite element codes to provide a more realistic analysis of deformation during blade-out events for fan containment systems composed of composite materials. While all of the loading conditions present in an impact situation may not be present in the current model (such as out-of-plane loading and fatigue loading), the current analysis techniques can still provide insight into the strain rate dependent deformation of composites under an impact situation. Immediate future efforts, not including other longer term future efforts discussed in earlier parts of this report, will include adding the ability to account for thermal effects to the polymer constitutive equations. The micromechanics will also be modified to allow for the analysis of woven and braided composites.

\section{References}

1. Goldberg, R.K.: "Strain Rate Dependent Deformation and Strength Modeling of a Polymer Matrix Composite Utilizing a Micromechanics Approach."

NASA/TM-1999-209768, 1999.

2. Stouffer, D.C.; and Dame, L.T.: Inelastic Deformation of Metals. Models, Mechanical Properties and Metallurgy. John Wiley and Sons, New York, 1996. 
3. Wineman, A.S.; and Rajagopal, K.R.: Mechanical Response of Polymers. Cambridge University Press, New York, 2000.

4. Ward, I.M.: Mechanical Properties of Solid Polymers. John Wiley and Sons, New York, 1983.

5. Bodner, S.R.: Unified Plasticity for Engineering Applications. Kluwer Academic/Plenum Publishers, New York, 2002.

6. Sun, C.T.; and Chen, J.L.: “A Simple Flow Rule for Characterizing Nonlinear Behavior of Fiber Composites.” Journal of Composite Materials, Vol. 23, pp. 1009$1020,1989$.

7. Weeks, C.A.; and Sun, C.T.: "Modeling Non-Linear Rate-Dependent Behavior in Fiber-Reinforced Composites." Composites Science and Technology, Vol. 58, pp. 603-611, 1998.

8. Thiruppukuzhi, S.V.; and Sun, C.T.: "Testing and modeling high strain rate behavior of polymeric composites." Composites Part B, Vol. 29B, pp. 535-546, 1998.

9. Yoon, K.J.; and Sun, C.T.: "Characterization of Elastic-Viscoplastic Properties of an AS4/PEEK Thermoplastic Composite." Journal of Composite Materials, Vol. 25, pp. 1277-1296, 1991.

10. Sun, C.T.; and Chen, J.L.: "A Micromechanical Model for Plastic Behavior of Fibrous Composites." Composites Science and Technology, Vol. 40, pp. 115-129, 1991.

11. Zhang, C.; and Moore, I.D.: "Nonlinear Mechanical Response of High Density Polyethylene. Part II: Uniaxial Constitutive Model." Polymer Engineering and Science, Vol. 37, pp. 414-420, 1997.

12. Bordonaro, C.M.: "Rate Dependent Mechanical Behavior of High Strength Plastics: Experiment and Modeling." PhD Dissertation, Rensselaer Polytechnic Institute, Troy, New York, 1995.

13. Krempl, E.; and Ho, K.: “An Overstress Model for Solid Polymer Deformation Behavior Applied to Nylon 66." Time Dependent and Nonlinear Effects in Polymers and Composites. ASTM STP 1357, R.A. Schapery and C.T. Sun, eds., American Society for Testing and Materials, West Conshohocken, PA, pp. 118-137, 2000.

14. Miller, E.: Introduction to Plastics and Composites. Mechanical Properties and Engineering Applications. Marcel Dekker, Inc., New York, 1996. 
15. Ellyin, F.; Hu, Y.; and Xia, Z.: "Multiaxial Behavior and Viscoelastic Constitutive Modeling of Epoxy Polymers." Recent Trends in Constitutive Modeling of Advanced Materials, AMD-Vol. 239, American Society for Mechanical Engineers, New York, pp. 13-25, 2000.

16. Hung, S.-C.; and Liechti, K.M.: "Nonlinear Multiaxial Behavior and Failure of Fiber-Reinforced Composites." Time Dependent and Nonlinear Effects in Polymers and Composites. ASTM STP 1357, R.A. Schapery and C.T. Sun, eds., American Society for Testing and Materials, West Conshohocken, PA, pp. 176-222, 2000.

17. Li, F.Z; and Pan, J.: "Plane-Stress Crack-Tip Fields for Pressure-Sensitive Dilatant Materials." Journal of Applied Mechanics, Vol. 57, pp. 40-49, 1990.

18. Chang, W.J.; and Pan, J.: "Effects of Yield Surface Shape and Round-Off Vertex on Crack-Tip Fields for Pressure-Sensitive Materials." International Journal of Solids and Structures, Vol. 34, pp. 3291-3320, 1997.

19. Hsu, S.-Y., Vogler, T.J.; and Kyriakides, S.: "Inelastic behavior of an AS4/PEEK composite under combined transverse compression and shear. Part II: modeling. International Journal of Plasticity, Vol. 15, pp. 807-836, 1999.

20. Khan, A.S.; and Huang, S.: Continuum Theory of Plasticity. John Wiley and Sons, Inc., New York, 1995.

21. Qian, Z.; and Liu, S.: "Unified Constitutive Modeling from Viscoelasticity and Viscoplasticity of Polymer Matrix Composites." Proceedings of the American Society for Composites Twelfth Technical Conference. R.F. Gibson and G.M. Newaz, eds., Technomic Publishing Co., Lancaster, PA, pp. 165-174, 1997.

22. Dowling, N.E.: Mechanical Behavior of Materials. Engineering Methods for Deformation, Fracture and Fatigue, Second Edition. Prentice Hall, Upper Saddle River, New Jersey, 1999.

23. Kreyszig, E.: Advanced Engineering Mathematics, $7^{\text {th }}$ Edition. John Wiley and Sons, Inc., New York, 1992.

24. Goldberg, R.K.: Computational Simulation of the High Strain Rate Tensile Response of Polymer Matrix Composites. NASA/TM-2002-211489, 2002.

25. Whitney, J.M.: "A Laminate Analogy for Micromechanics." Proceedings of the American Society for Composites Eighth Technical Conference, G.M. Newaz, ed., Technomic Publishing Co., Lancaster, PA, pp. 785-794, 1993. 
26. Greszcuk, L.B.: "Interfiber Stresses in Filamentary Composites." AIAA Journal, Vol. 9, pp. 1274-1280, 1971.

27. Mital, S.K.; Murthy, P.L.N.; and Chamis, C.C.: "Micromechanics for Ceramic Matrix Composites Via Fiber Substructuring." Journal of Composite Materials, Vol. 29, pp. 614-633, 1995.

28. Murthy, P.L.N.; Ginty, C.A.; and Sanfeliz, J.G.: "Second Generation Integrated Composite Analyzer (ICAN) Computer Code.” NASA TP-3290, 1993. 
TABLE 1.-MATERIAL PROPERTIES FOR POLYMER MATRIX MATERIALS

\begin{tabular}{|c|c|c|c|c|c|c|c|c|c|c|}
\hline & $\begin{array}{l}\text { Strain } \\
\text { Rate } \\
\text { /sec }\end{array}$ & $\begin{array}{l}\text { Modulus } \\
\text { GPa }\end{array}$ & $\begin{array}{c}\text { Poisson's } \\
\text { Ratio }\end{array}$ & $\begin{array}{c}D_{o} \\
1 / \mathrm{sec}\end{array}$ & $\mathrm{n}$ & $\begin{array}{c}\mathrm{Z}_{\mathrm{o}} \\
\mathrm{MPa}\end{array}$ & $\begin{array}{c}\mathrm{Z}_{1} \\
\mathrm{MPa}\end{array}$ & q & $\alpha_{0}$ & $\alpha_{1}$ \\
\hline \multirow[t]{3}{*}{ PR520 } & 0.00001 & 3.24 & \multirow[t]{3}{*}{0.38} & \multirow[t]{3}{*}{$1 \times 10^{6}$} & \multirow[t]{3}{*}{0.92} & \multirow[t]{3}{*}{402.53} & \multirow[t]{3}{*}{766.73} & \multirow[t]{3}{*}{247.44} & \multirow[t]{3}{*}{0.983} & \multirow[t]{3}{*}{0.209} \\
\hline & 1.4 & 4.15 & & & & & & & & \\
\hline & 450 & 5.65 & & & & & & & & \\
\hline \multirow[t]{3}{*}{ E-862 } & 0.00001 & 2.93 & \multirow[t]{3}{*}{0.38} & \multirow[t]{3}{*}{$1 \times 10^{6}$} & \multirow[t]{3}{*}{0.80} & \multirow[t]{3}{*}{436.59} & \multirow[t]{3}{*}{842.80} & \multirow[t]{3}{*}{134.10} & \multirow[t]{3}{*}{0.882} & \multirow[t]{3}{*}{0.161} \\
\hline & 1.4 & 3.26 & & & & & & & & \\
\hline & 450 & 5.17 & & & & & & & & \\
\hline PEEK & All & 4.00 & 0.40 & $1 \times 10^{6}$ & 1.25 & 231.67 & 596.94 & 254.68 & 0.200 & 0.077 \\
\hline
\end{tabular}




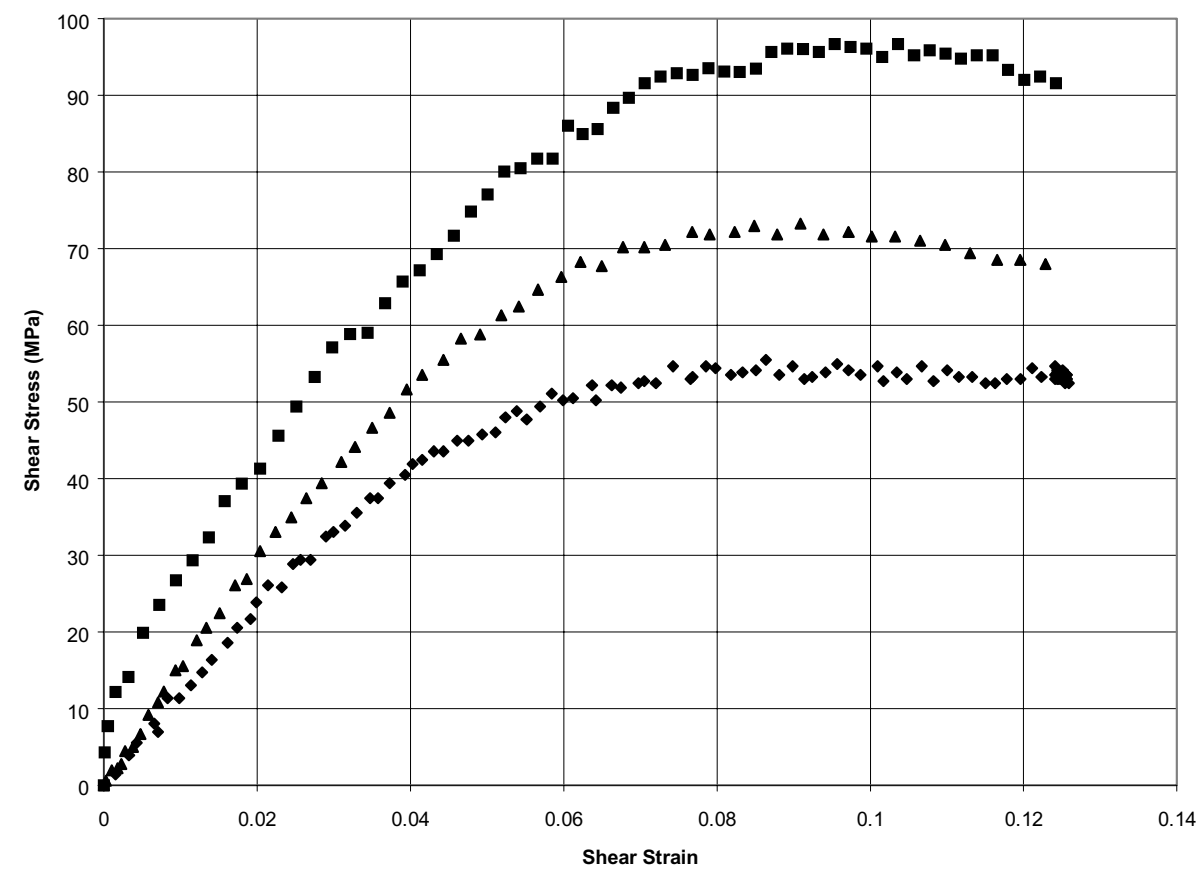

Experiment- $7.5 \times 10-5 / \mathrm{sec}$

$\Delta$ Experiment- $1.5 / \mathrm{sec}$

Experiment- $404 / \mathrm{sec}$

Figure 1: Experimental shear stress-shear strain curves for PR520 resin at strain rates of $7.5 \times 10^{-5} / \mathrm{sec}, 1.5 / \mathrm{sec}$ and $404 / \mathrm{sec}$.

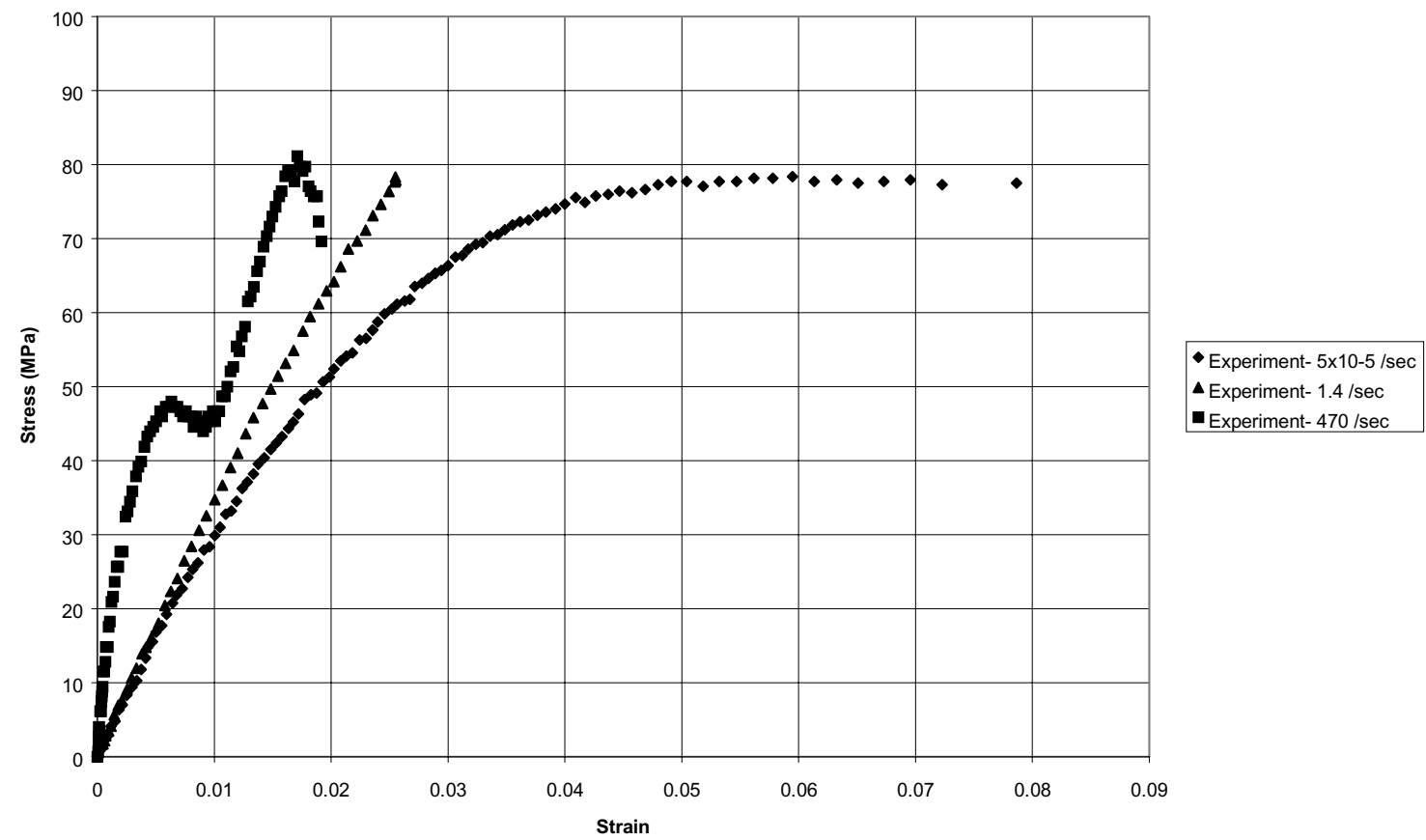

Figure 2: Experimental tensile stress-strain curves for PR520 resin at strain rates of $5 \times 10^{-5} / \mathrm{sec}, 1.4 / \mathrm{sec}$ and $470 / \mathrm{sec}$. 


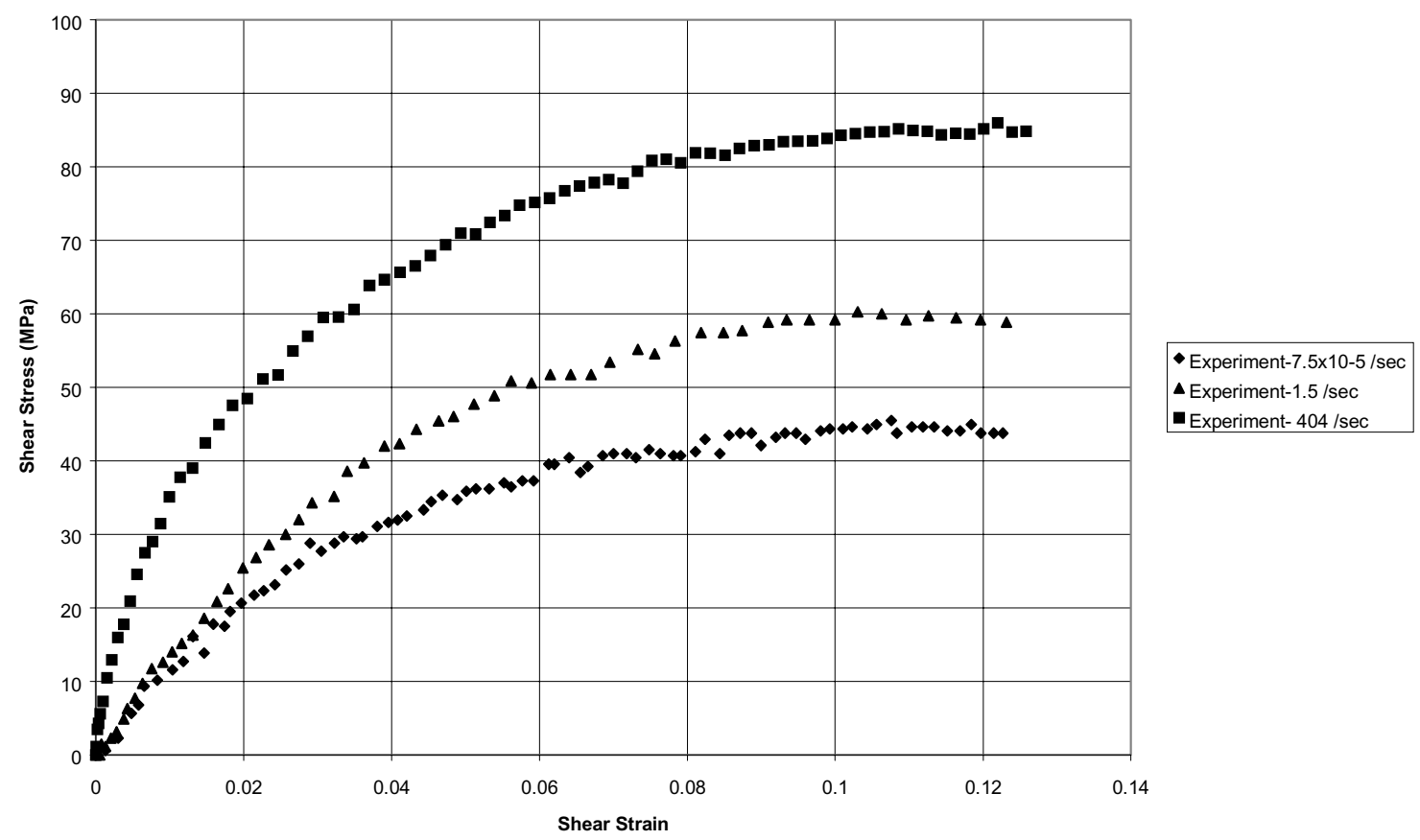

Figure 3: Experimental shear stress-shear strain curves for E-862 resin at strain rates of $7.5 \times 10^{-5} / \mathrm{sec}, 1.5 / \mathrm{sec}$ and $404 / \mathrm{sec}$.

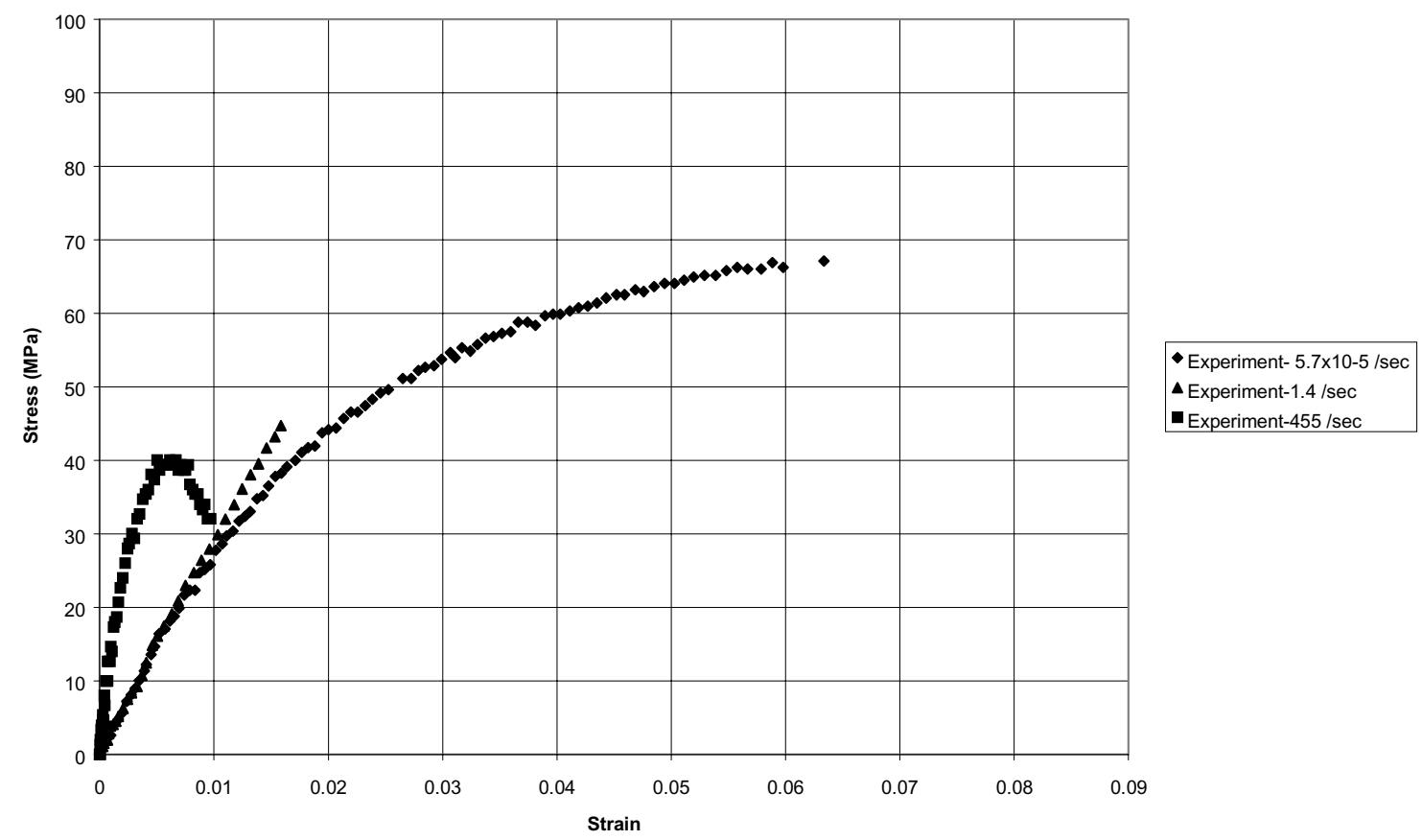

Figure 4: Experimental tensile stress-strain curves for E-862 resin at strain rates of $5.7 \times 10^{-5} / \mathrm{sec}, 1.4 / \mathrm{sec}$ and $455 / \mathrm{sec}$. 


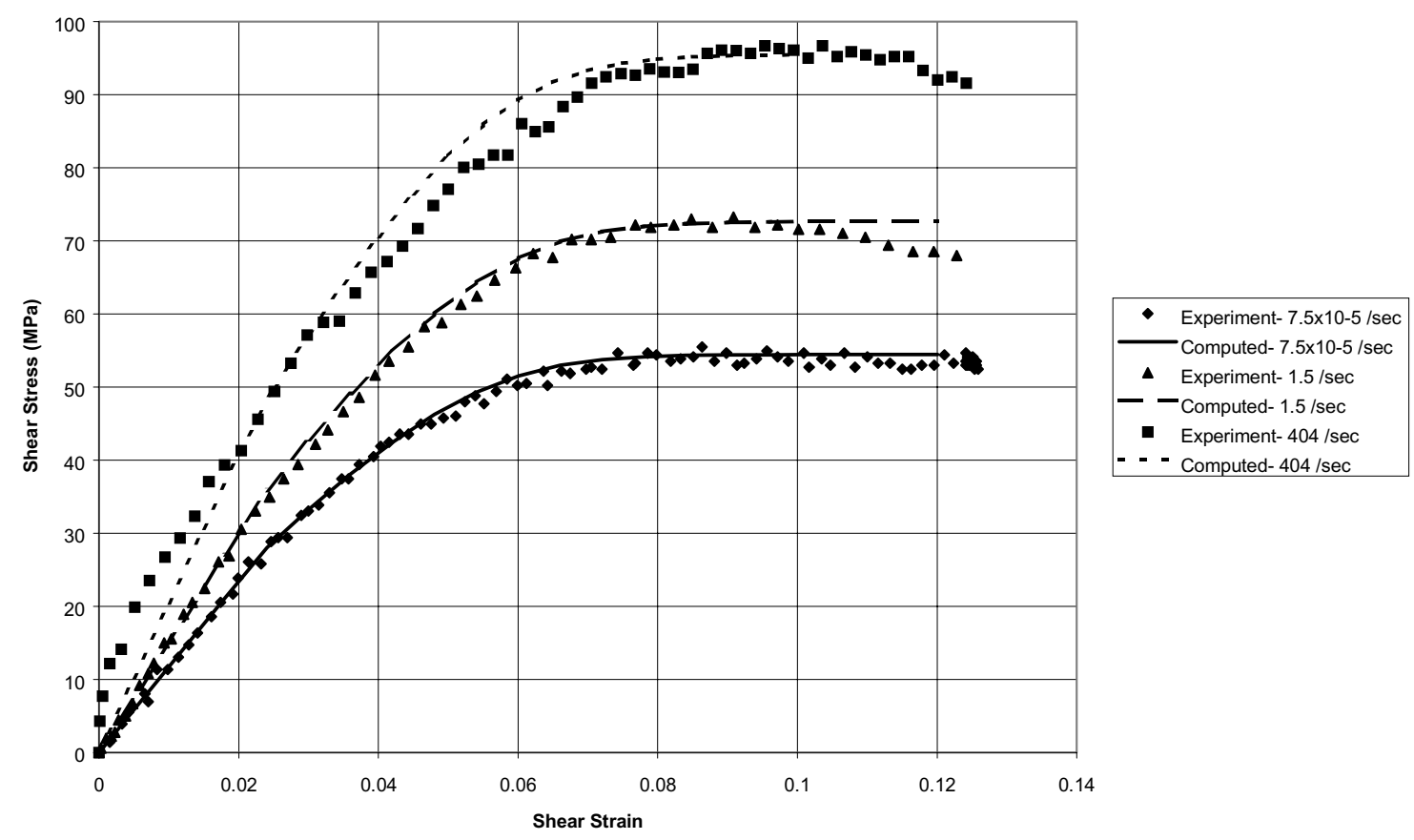

Figure 5: Experimental and computed shear stress-shear strain curves for PR520 resin at strain rates of $7.5 \times 10^{-5} / \mathrm{sec}, 1.5 / \mathrm{sec}$ and $404 / \mathrm{sec}$.

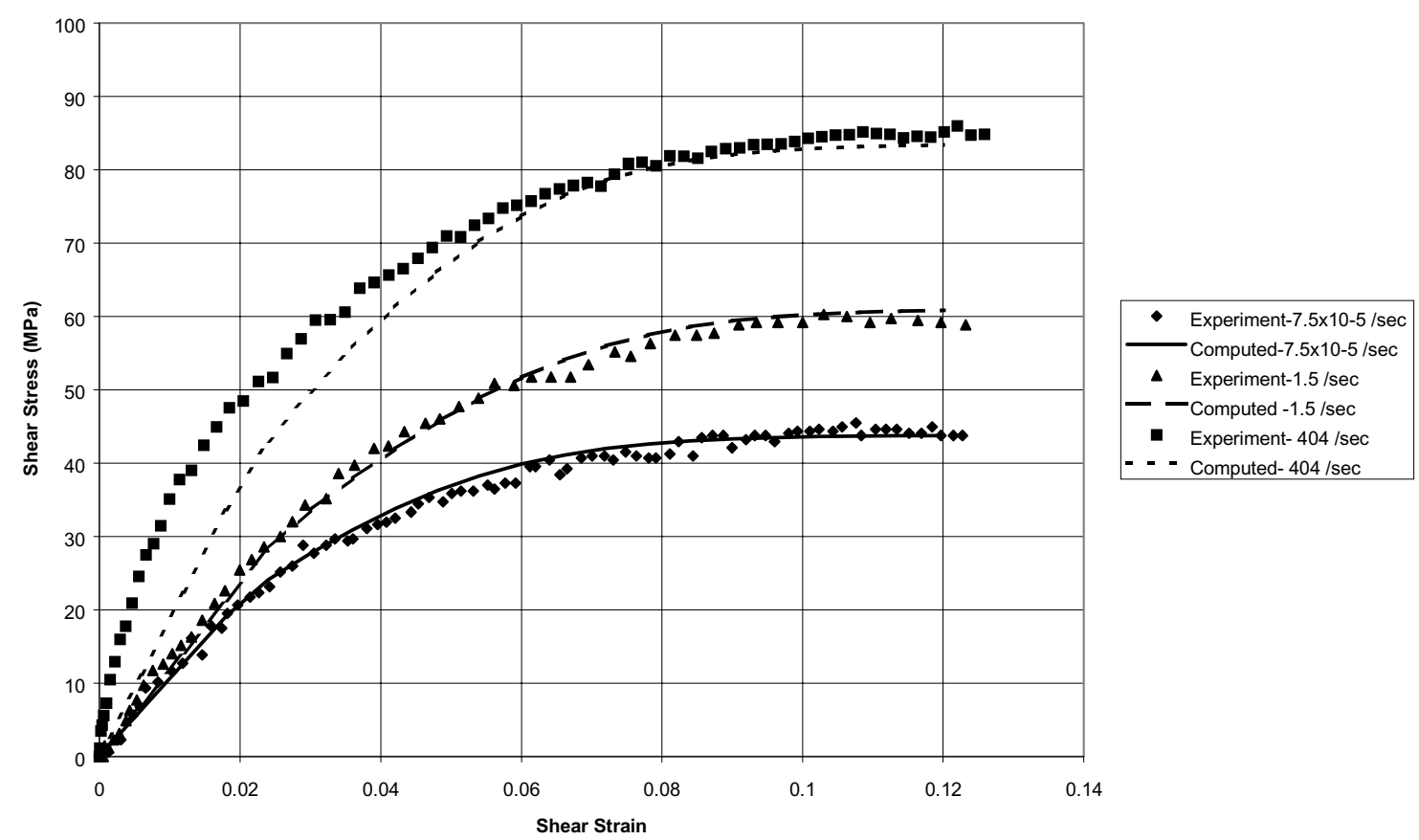

Figure 6: Experimental and computed shear stress-shear strain curves for E-862 resin at strain rates of $7.5 \times 10^{-5} / \mathrm{sec}, 1.5 / \mathrm{sec}$ and $404 / \mathrm{sec}$. 


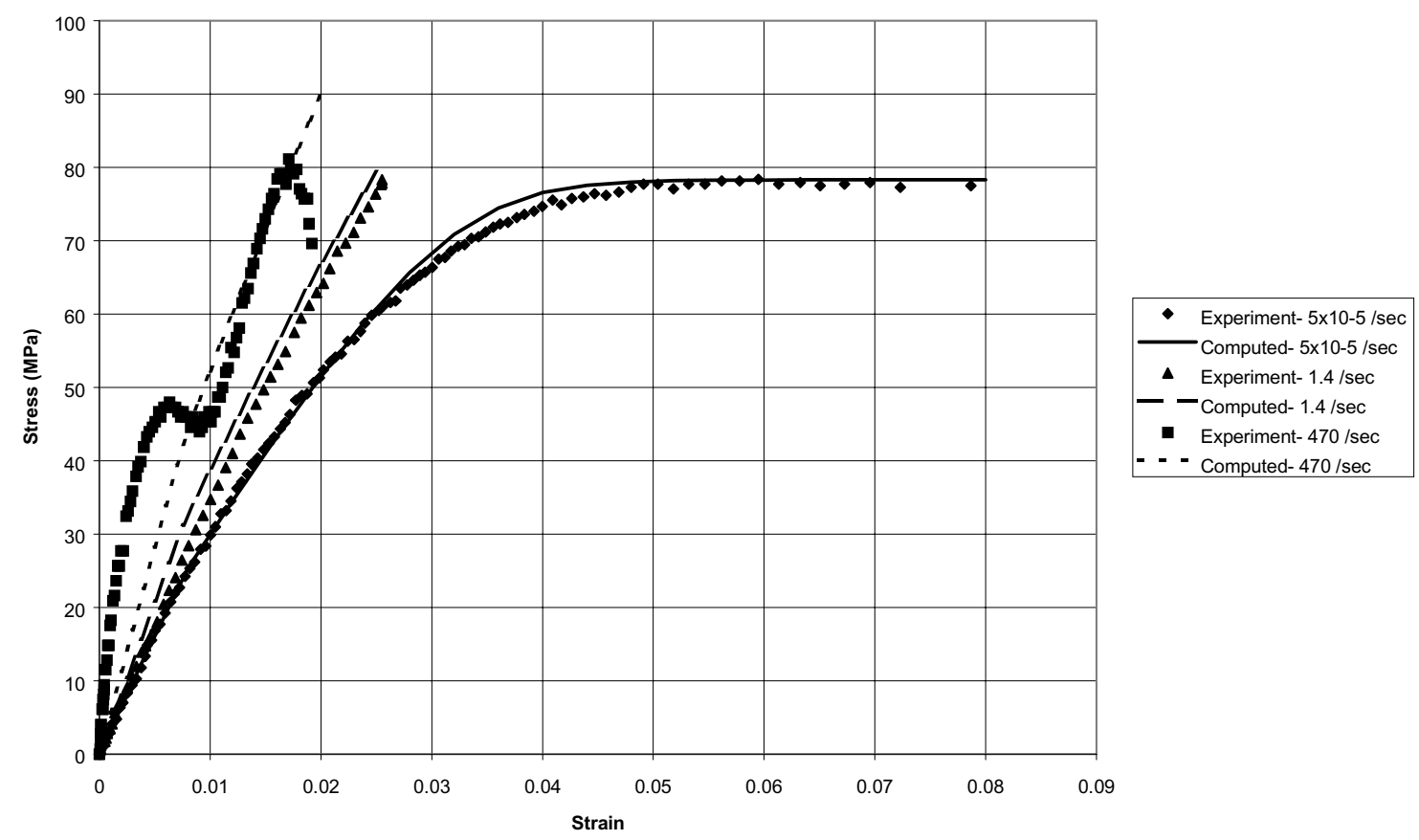

Figure 7: Experimental and computed tensile stress-strain curves for PR520 resin at strain rates of $5 \times 10^{-5} / \mathrm{sec}, 1.4 / \mathrm{sec}$ and $470 / \mathrm{sec}$.

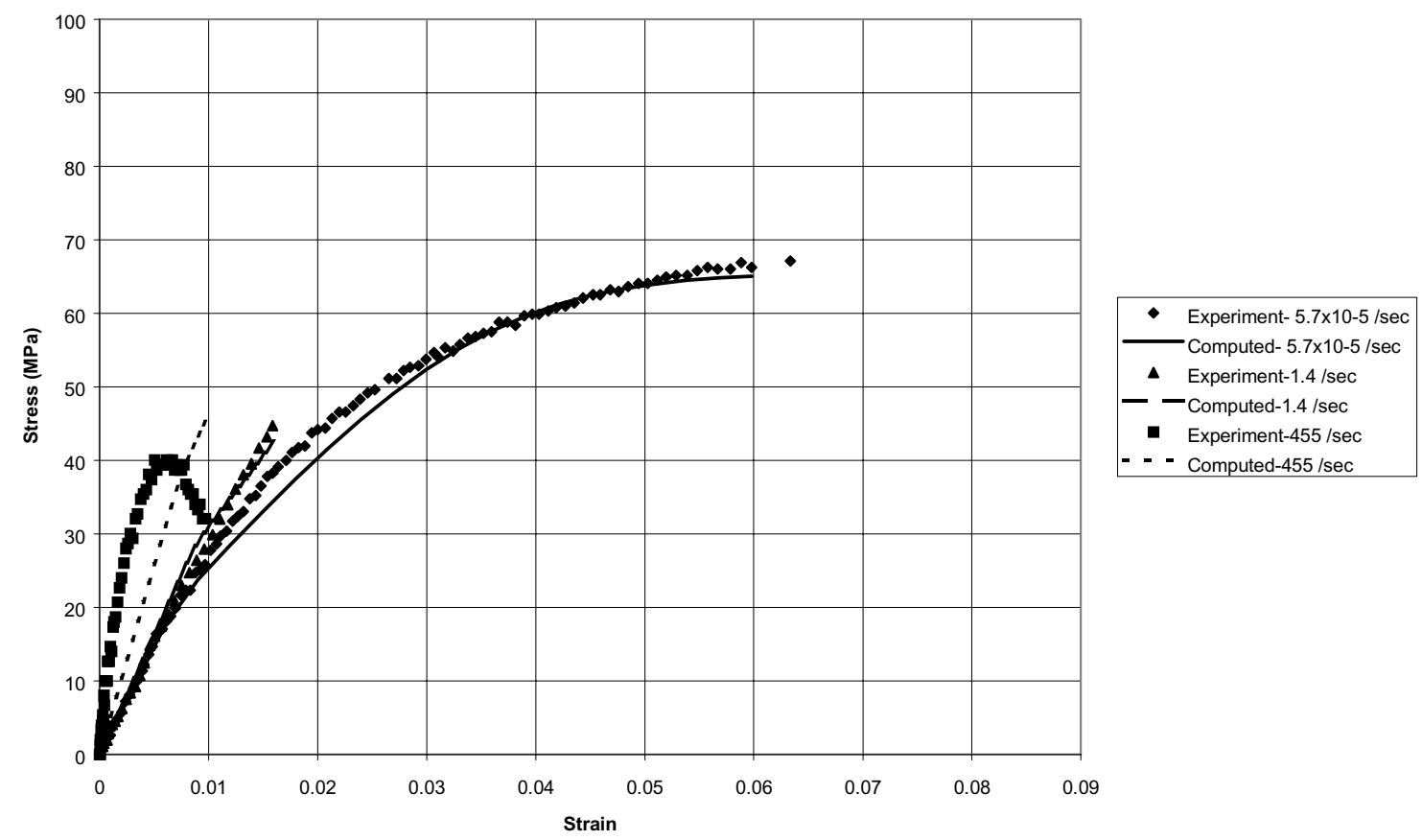

Figure 8: Experimental and computed tensile stress-strain curves for E-862 resin at strain rates of $5.7 \times 10^{-5} / \mathrm{sec}, 1.4 / \mathrm{sec}$ and $455 / \mathrm{sec}$. 


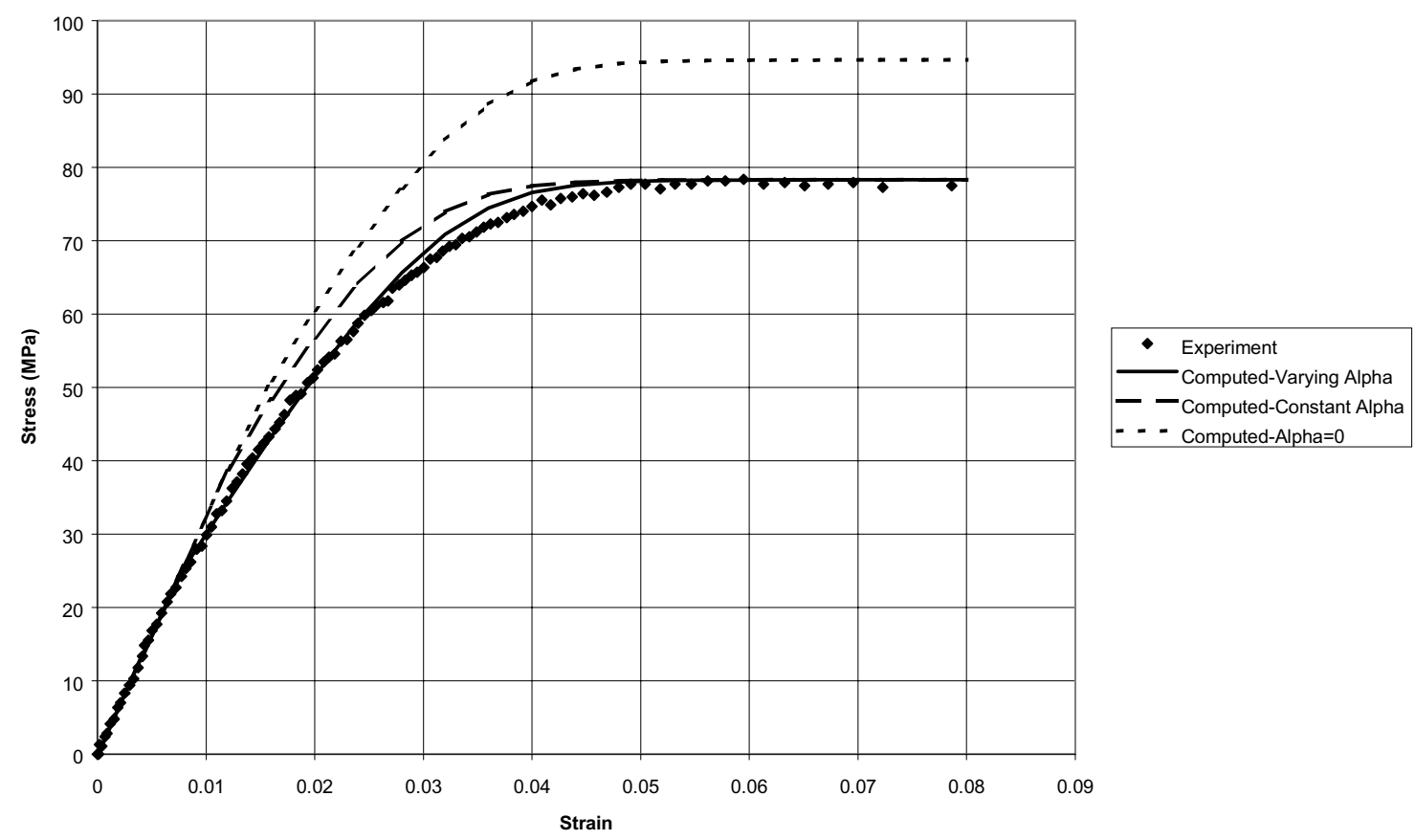

Figure 9: Effect of mean stress effect variable $\alpha$ on tensile stress-strain curve for PR520 resin at $5 \times 10^{-5} / \mathrm{sec}$.

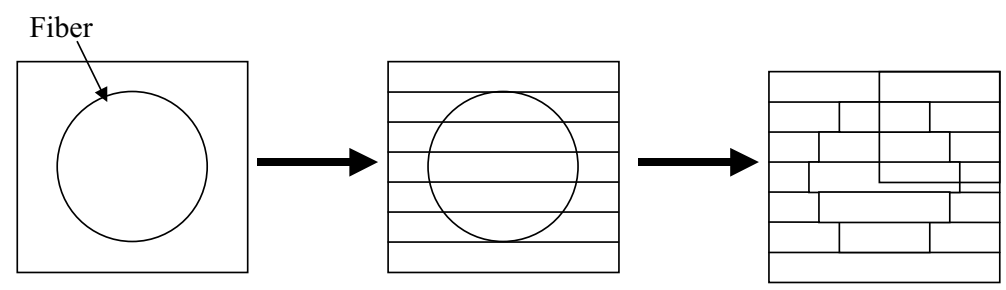

Unit Cell

Sliced Unit Cell Circular Fiber

Sliced Unit Cell

Rectangular Fiber Slices
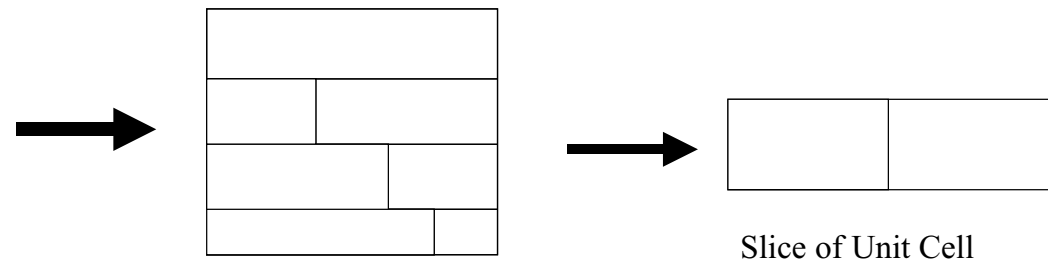

Slice of Unit Cell

Portion of Sliced Unit Cell Analyzed

Figure 10: Schematic showing relationship between unit cell and slices for micromechanics. 


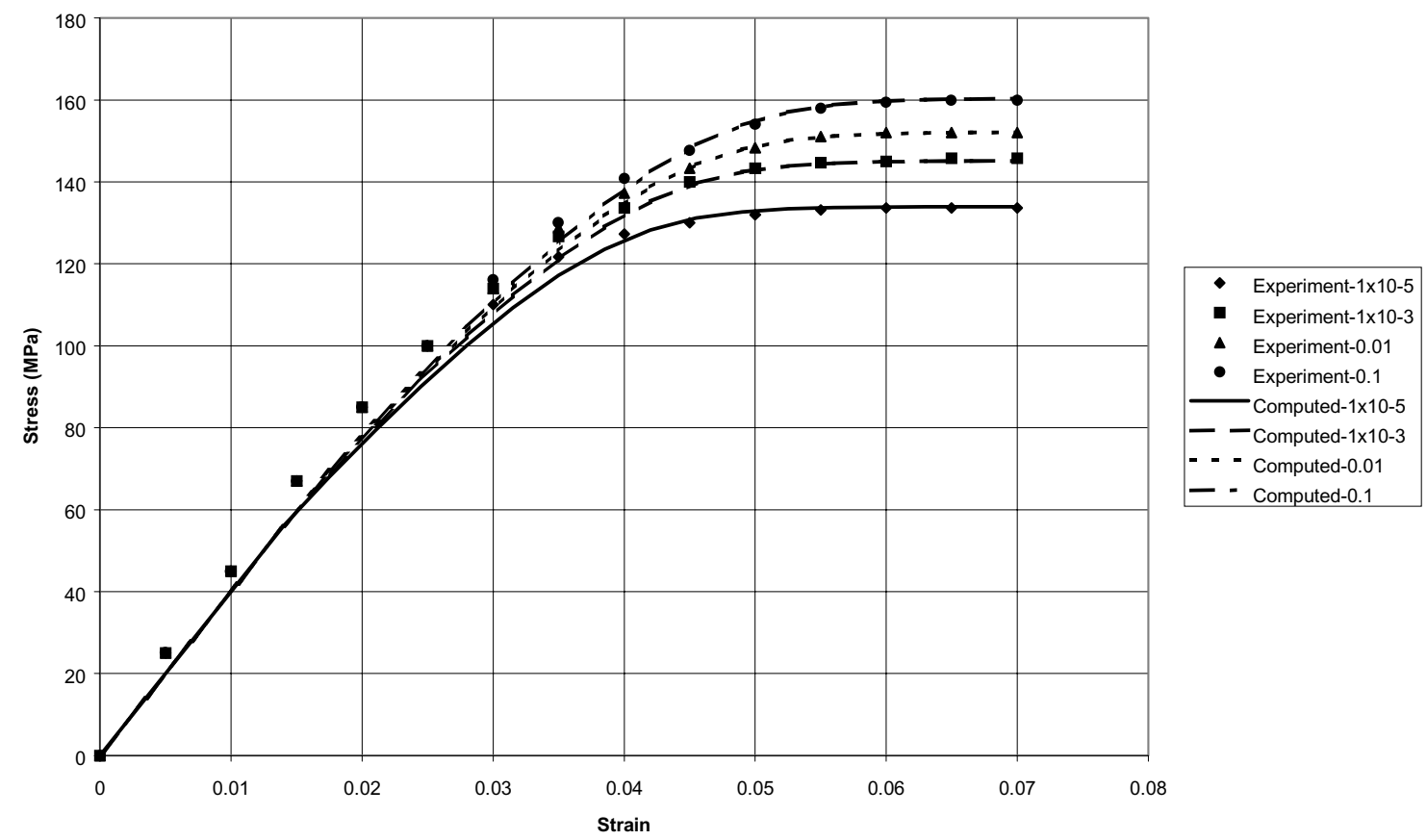

Figure 11: Experimental and computed compressive stress-strain curves for PEEK thermoplastic at strain rates of $1 \times 10^{-5} / \mathrm{sec}, 1 \times 10^{-3} / \mathrm{sec}, 0.01 / \mathrm{sec}$ and $0.1 / \mathrm{sec}$.

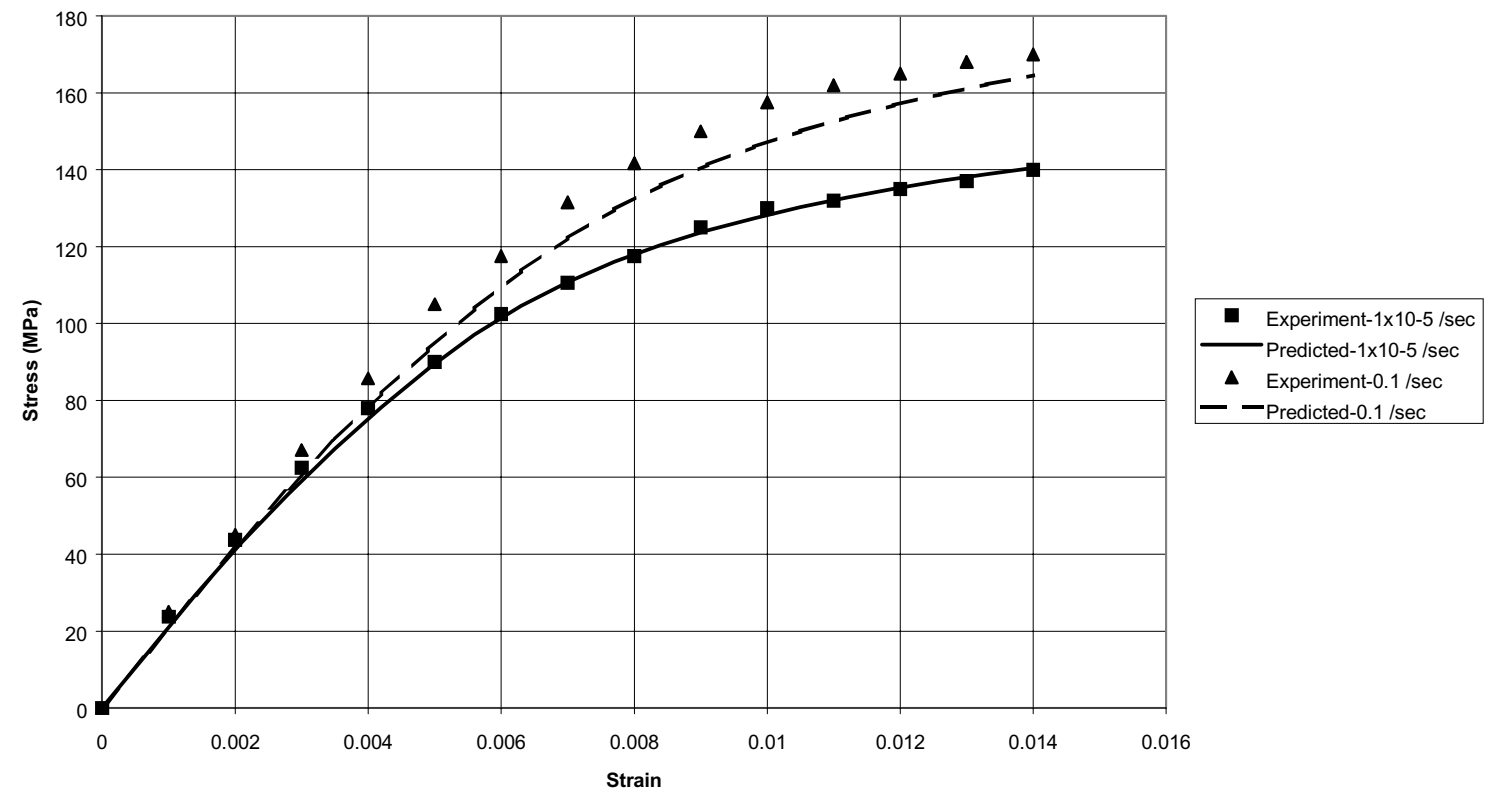

Figure 12: Experimental and predicted tensile stress-strain curves for AS4/PEEK [30 $\left.{ }^{\circ}\right]$ laminates at strain rates of $1 \times 10^{-5} / \mathrm{sec}$ and $0.1 / \mathrm{sec}$. 


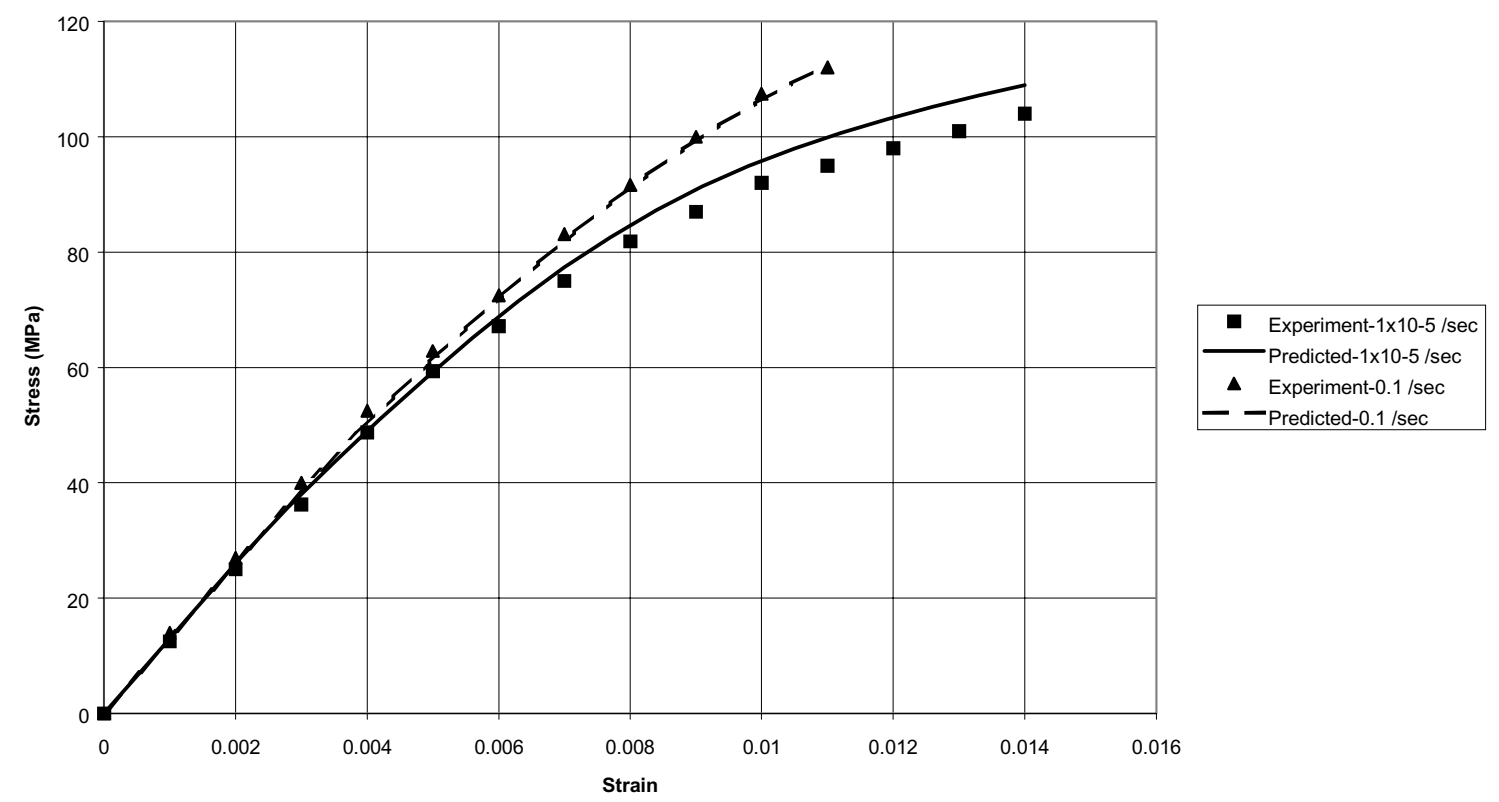

Figure 13: Experimental and predicted tensile stress-strain curves for AS4/PEEK [45 $]$ laminates at strain rates of $1 \times 10^{-5} / \mathrm{sec}$ and $0.1 / \mathrm{sec}$. 
Public reporting burden for this collection of information is estimated to average 1 hour per response, including the time for reviewing instructions, searching existing data sources, gathering and maintaining the data needed, and completing and reviewing the collection of information. Send comments regarding this burden estimate or any other aspect of this collection of information, including suggestions for reducing this burden, to Washington Headquarters Services, Directorate for Information Operations and Reports, 1215 Jefferson Davis Highway, Suite 1204, Arlington, VA 22202-4302, and to the Office of Management and Budget, Paperwork Reduction Project (0704-0188), Washington, DC 20503.

\begin{tabular}{|l|l|l}
\hline 1. AGENCY USE ONLY (Leave blank) & $\begin{array}{c}\text { 2. REPORT DATE } \\
\text { June } 2002\end{array}$ & $\begin{array}{r}\text { 3. REPORT TYPE AND DATES COVERED } \\
\text { Technical Memorandu }\end{array}$
\end{tabular}

\section{TITLE AND SUBTITLE}

5. FUNDING NUMBERS

Incorporation of Mean Stress Effects Into the Micromechanical Analysis of the

High Strain Rate Response of Polymer Matrix Composites

6. AUTHOR(S)

Robert K. Goldberg, Gary D. Roberts, and Amos Gilat

WU-708-24-13-00

\section{PERFORMING ORGANIZATION NAME(S) AND ADDRESS(ES)}

National Aeronautics and Space Administration

John H. Glenn Research Center at Lewis Field

Cleveland, Ohio 44135-3191

8. PERFORMING ORGANIZATION

REPORT NUMBER

E-13447

\section{SPONSORING/MONITORING AGENCY NAME(S) AND ADDRESS(ES)}

10. SPONSORING/MONITORING

AGENCY REPORT NUMBER

National Aeronautics and Space Administration

Washington, DC 20546-0001

NASA TM-2002-211702

\section{SUPPLEMENTARY NOTES}

Prepared for the Ninth International Conference on Composites Engineering sponsored by the International Community for Composites Engineering, San Diego, California, July 1-6, 2002. Robert K. Goldberg and Gary D. Roberts, NASA Glenn Research Center; Amos Gilat, Ohio State University, Columbus, Ohio 43210. Responsible person, Robert K. Goldberg, organization code 5920, 216-433-3330.

12a. DISTRIBUTION/AVAILABILITY STATEMENT 12b. DISTRIBUTION CODE

Unclassified - Unlimited

Subject Category: 24

Distribution: Nonstandard

Available electronically at http://gltrs.grc.nasa.gov/GLTRS

This publication is available from the NASA Center for AeroSpace Information, 301-621-0390.

13. ABSTRACT (Maximum 200 words)

The results presented here are part of an ongoing research program, to develop strain rate dependent deformation and failure models for the analysis of polymer matrix composites subject to high strain rate impact loads. A micromechanics approach is employed in this work, in which state variable constitutive equations originally developed for metals have been modified to model the deformation of the polymer matrix, and a strength of materials based micromechanics method is used to predict the effective response of the composite. In the analysis of the inelastic deformation of the polymer matrix, the definitions of the effective stress and effective inelastic strain have been modified in order to account for the effect of hydrostatic stresses, which are significant in polymers. Two representative polymers, a toughened epoxy and a brittle epoxy, are characterized through the use of data from tensile and shear tests across a variety of strain rates. Results computed by using the developed constitutive equations correlate well with data generated via experiments. The procedure used to incorporate the constitutive equations within a micromechanics method is presented, and sample calculations of the deformation response of a composite for various fiber orientations and strain rates are discussed.

\begin{tabular}{|c|c|c|}
\hline \multicolumn{3}{|c|}{$\begin{array}{l}\text { 14. SUBJECT TERMS } \\
\text { Polymer matrix composites; Constitutive equations; Strain rate; Viscoplasticity; Impact; } \\
\text { Micromechanics }\end{array}$} \\
\hline $\begin{array}{l}\text { 17. SECURITY CLASSIFICATION } \\
\text { OF REPORT }\end{array}$ & $\begin{array}{l}\text { 18. SECURITY CLASSIFICATION } \\
\text { OF THIS PAGE }\end{array}$ & $\begin{array}{l}\text { 19. SECURITY CLASSIFICATION } \\
\text { OF ABSTRACT }\end{array}$ \\
\hline & & \\
\hline
\end{tabular}



